\title{
Diversidad y endemismo de los mamíferos del Perú
}

\section{Diversity and endemism of Peruvian mammals}

\author{
Víctor Pacheco ${ }^{1,2}$, Richard Cadenillas ${ }^{1}$, Edith Salas ${ }^{1}$, Carlos Tello ${ }^{1}$ y Horacio Zeballos ${ }^{3}$
}

\begin{abstract}
1 Museo de Historia Natural, Universidad Nacional Mayor de San Marcos, Apartado 14-0434, Lima14, Perú. Email Víctor Pacheco: vpachecot@unmsm.edu.pe

2 Facultad de Ciencias Biológicas, Universidad Nacional Mayor de San Marcos.

3 Centro de Estudios y Promoción del Desarrollo, DESCO, Málaga Grenet 678, Umacollo, Arequipa.
\end{abstract}

Presentado: $11 / 05 / 2009$ Aceptado: 15/06/2009 Publicado online: 28/08/2009

\section{Resumen}

Se presenta una lista comentada de los mamíferos terrestres, acuáticos y marinos nativos de Perú, incluyendo sus nombres comunes, la distribución por ecorregiones y los estados de amenaza según la legislación nacional vigente y algunos organismos internacionales. Se documenta 508 especies nativas, en 13 órdenes, 50 familias y 218 géneros; resultando el Perú como el tercer país con la mayor diversidad de especies en el Nuevo Mundo después de Brasil y México, así como quinto en el mundo. Esta diversidad incluye a 40 didelfimorfos, 2 paucituberculados, 1 sirenio, 6 cingulados, 7 pilosos, 39 primates, 162 roedores, 1 lagomorfo, 2 soricomorfos, 165 quirópteros, 34 carnívoros, 2 perisodáctilos y 47 cetartiodáctilos. Los roedores y murciélagos (327 especies) representan casi las dos terceras partes de la diversidad (64\%). Cinco géneros y 65 especies $(12,8 \%)$ son endémicos para Perú, siendo la mayoría de ellos roedores (45 especies, 69,2\%). La mayoría de especies endémicas se encuentra restringida a las Yungas de la vertiente oriental de los Andes (39 especies, $60 \%$ ) seguida de lejos por la Selva Baja (14 especies, $21,5 \%$ ). Se comenta la taxonomía de algunas especies, cuando éstas discrepan de la taxonomía aceptada. El marsupial Marmosa phaea; los roedores Melanomys caliginosus, M. robustulus y Echinoprocta rufescens; la musaraña Cryptotis equatoris; los murciélagos Anoura fistulata, Phyllostomus latifolius, Artibeus ravus, Cynomops greenhalli, Eumops maurus y Rhogeessa velilla; y el carnívoro Nasuella olivacea son primeros registros para el Perú. Finalmente, se incluye una lista de 15 especies introducidas.

Palabras clave: Mamíferos, Perú, diversidad, endemismo, conservación.

\section{Abstract}

We present an annotated list for all land, aquatic and marine mammals known to occur in Peru and their distribution by ecoregions. We also present species conservation status according to international organizations and the legal conservation status in Peru. At present, we record 508 species, in 13 orders, 50 families, and 218 genera, making Peru the third most diverse country with regards to mammals in the New World, after Brazil and Mexico, and the fifth most diverse country for mammals in the World. This diversity includes 40 didelphimorphs, 2 paucituberculates, 1 manatee, 6 cingulates, 7 pilosa, 39 primates, 162 rodents, 1 rabbit, 2 soricomorphs, 165 bats, 34 carnivores, 2 perissodactyls, and 47 cetartiodactyls. Bats and rodents ( 327 species) represent almost two thirds of total diversity (64\%) for Peru. Five genera and 65 species $(12.8 \%)$ are endemics to Peru, with the majority of these being rodents (45 species, $69,2 \%$ ). Most of the endemic species are restricted to the Yungas of the eastern slope of the Andes ( 39 species, $60 \%$ ) followed by Selva Baja (14 species, 21.5\%). The taxonomic status of some species is commented on, when those depart from accepted taxonomy. The marsupial Marmosa phaea; the rodents Melanomys caliginosus, M. robustulus, and Echinoprocta rufescens; the shrew Cryptotis equatoris; the bats Anoura fistulata, Phyllostomus latifolius, Artibeus ravus, Cynomops greenhalli, Eumops maurus, and Rhogeessa velilla; and the carnivore Nasuella olivacea are first records of species occurrence in Peru. Finally, we also include a list of 15 non-native species.

Keywords: Mammals, Peru, diversity, endemism, conservation.

\section{Introducción}

Recientemente, dos volúmenes de gran trascendencia para la mastozoología neotropical han sido publicados: Mammal Species of the World, en su tercera edición por Wilson y Reeder (2005) y Mammals of South America, volumen 1 editado por Gardner (2008). Estas obras presentan información actualizada sobre la taxonomía y distribución de las especies y constituyen un punto de inicio indispensable para listados detallados a nivel regional.

La última compilación de mamíferos nativos para Perú reportó 460 especies (Pacheco et al. 1995). Después de casi tres lustros los cambios taxonómicos ocurridos hasta el presente son numerosos, a nivel de especie, género, familia, e incluso orden. Bastan unos pocos ejemplos como ilustración; así el antiguo orden Xenarthra fue dividido en Cingulata y Pilosa, y el orden Insectivora en Afrosoricida, Erinaceomorpha y Soricomorpha (Wilson y Reeder 2005). A nivel de género, Oryzomys fue separado recientemente en 10 géneros válidos (Weksler et al. 2006); y en otro ejemplo reciente, Velazco (2005) reporta cuatro nuevas especies en un solo género, el murciélago Platyrrhinus. Revisiones taxonómicas más completas y extensas que incluyen diversas perspectivas como análisis moleculares y morfológicos, nuevos registros de distribución, una más estricta definición de taxa basada en monofilia, así como evaluaciones de sitios inexplorados son los responsables de estos cambios.

En este trabajo se presenta una lista actualizada de todas las especies de mamíferos silvestres sean terrestres, marinos o de agua dulce, conocidas para Perú hasta el presente. Para cada especie se incluyen datos de distribución según el mapa de las ecorregiones naturales definidas por Brack-Egg (1986), nombre común, situación de endemismo para el país y estado de conservación según organismos internacionales y la legislación peruana. Se provee finalmente un comentario sobre la conservación de los mamíferos en el Perú.

\section{Material y métodos}

El ordenamiento jerárquico desde orden hasta familia, y en algunos casos hasta subfamilia, es filogenético y basado en Wilson y Reeder (2005); con la excepción de que optamos por el orden Cetartiodactyla en lugar de los órdenes Cetacea y Artiodactyla, debido a la evidencia morfológica y molecular que concuerda en que los hipopótamos están más relacionados a los cetáceos que a otros artiodáctilos, convirtiendo a Artiodactyla en un grupo parafilético (Gatesy et al. 1999, Geisler y Uhen 2003, 2005, 


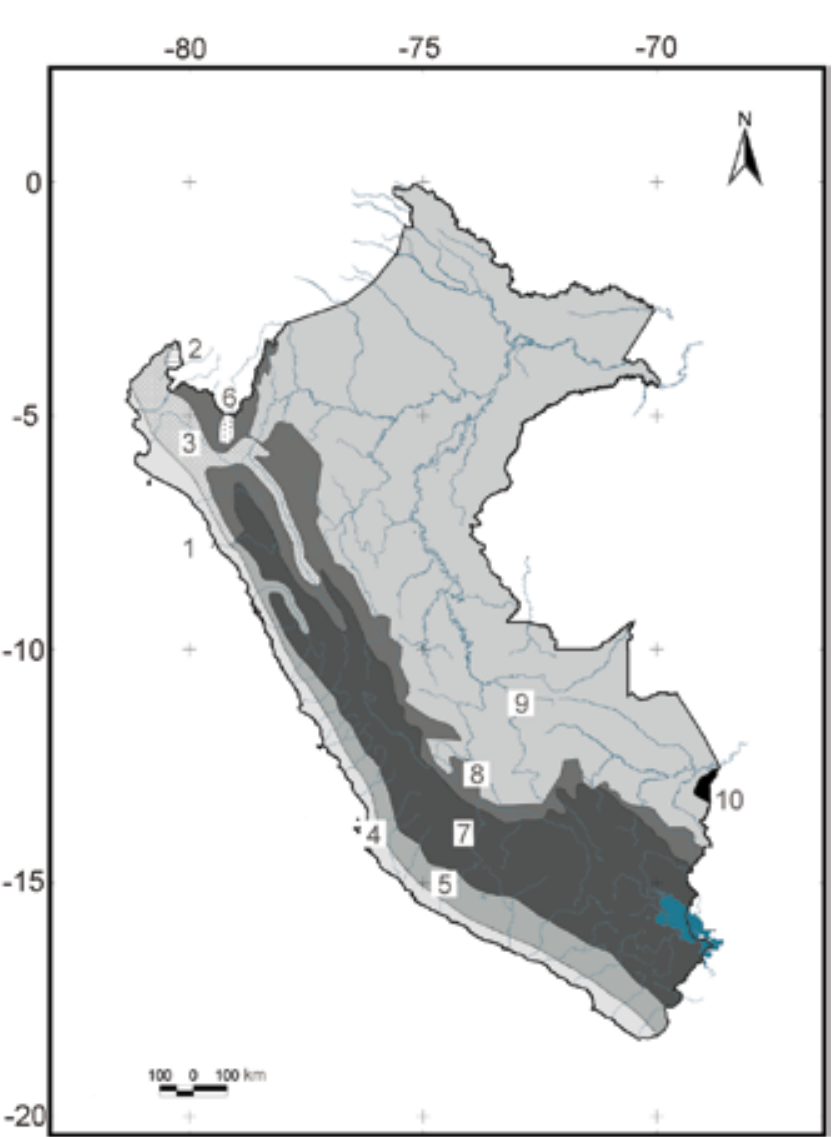

Figura 1. Ecorregiones del Perú según Brack-Egg (1986), empleadas para la distribución de los mamíferos. 1 = Oceánica, 2 = Bosque Pluvial del Pacífico, 3 = Bosque Seco Ecuatorial, 4 = Desierto Costero, 5 = Serranía Esteparia, 6 = Páramo, $7=$ Puna, $8=$ Yungas, $9=$ Selva Baja, 10 = Sabana de Palmera.

Boisserie et al. 2005, Waddell y Shelley 2003). Por otro lado, y reconociendo que aún existen discrepancias entre los estudiosos de insectívoros, optamos por el orden Soricomorpha siguiendo a Hutterer (2005). Lopatin (2006) propone otra alternativa al incluir a los insectívoros (excluyendo a los Tenrecoidea) en el orden Lipotyphla, considerando a Soricomorpha como un suborden. Como bien señala Lopatin (2006), el término Lipotyphla no requiere modificación a Eulipotyphla (sensu Waddell et al. 1999) para agrupar a estos insectívoros placentarios no-africanos.

Los géneros y especies se encuentran ordenados alfabéticamente y siguen la taxonomía de Wilson y Reeder (2005) o Gardner (2008); sin embargo, se incluyen notas taxonómicas cuando no concordamos con estos trabajos o existe información nueva recientemente publicada. Se incluyen registros nuevos para el país en base a las colecciones científicas del Museo de Historia Natural de la Universidad Nacional Mayor de San Marcos (MUSM) y del Museo de Historia Natural de la Universidad Nacional San Agustín (MUSA), los cuales se documentarán en extenso en otras publicaciones. Todas las especies mencionadas en el presente trabajo están sustentadas por al menos un espécimen o por una referencia bibliográfica. Especies potencialmente presentes en el país no han sido incluidas para no sobrestimar la biodiversidad del país. Sin embargo, sí se incluyen algunas especies consideradas nuevas para la ciencia (por expertos taxónomos) pero no reportadas aún.

Para ubicar la distribución de especies por ecorregiones se preparó una capa en base a la descripción original de Brack-Egg
(1986) con el programa ArcView 3.2 (Fig. 1), sobre el cual se sobrepusieron los registros de especies para determinar la ecorregión correspondiente.

El estado de conservación fue compilada en base a la lista de especies amenazadas según la legislación nacional vigente, el Decreto Supremo No 034-2004-AG (Ministerio de Agricultura 2004) y listas actualizadas de la organizaciones internacionales International Union for the Conservation of Nature (IUCN 2008) y Convention on International Trade in Endangered Species (CITES 2009). Además, las versiones IUCN 2006 y 2008 fueron comparadas para visualizar tendencias en el estado de conservación de las especies.

Se asignan nombres comunes para la mayoría de las especies siguiendo a Pacheco et al. (1995), Emmons y Feer (1999), Tirira (2004), ACOREMA (2009) o traduciendo los nombres ingleses encontrados en Grimwood (1969), Nowak (1999) o Wilson y Reeder (2005). En unos pocos casos se propone un nombre común cuando este no existe en la literatura haciendo referencia en lo posible al significado del nombre científico. Se incluyen también nombres vernaculares donde haya plena certeza de su uso. Nombres comunes en inglés pueden ser encontrados en numerosos trabajos (e.g., Emmons y Feer 1997, Linares 1987, Macdonald 1984, Nowak 1999, Wilson y Reeder 2005) por lo que no son incluidos aquí. Finalmente, se presenta una lista de mamíferos introducidos y domésticos en base a la literatura (Cossíos 2004, Del Río et al. 2001, Escomel 1929, Lleellish et al. 2007), siguiendo la nomenclatura propuesta por Gentry et al. (2004).

Para algunas especies se emplea las siguientes medidas estándar: $\mathrm{LT}=$ Longitud total, $\mathrm{LC}=$ Longitud de la cola, $\mathrm{LP}=$ Longitud del pie, $\mathrm{LO}=$ Longitud de la oreja, $\mathrm{CBL}=$ Longitud condilobasal, $\mathrm{ML}=$ Longitud de la hilera molar. Se incluyen también acrónimos de las siguientes instituciones: $\mathrm{AMNH}=$ American Museum of Natural History, New York; FMNH= Field Museum of Natural History, Chicago; ICN= Instituto de Ciencias Naturales de la Universidad Nacional de Colombia, Bogotá; LSUMZ= Louisiana State University, Museum of Zoology, Baton Rouge; $\mathrm{MVZ}=$ Museum of Vertebrate Zoology, University of California, Berkeley; MUSM= Museo de Historia Natural, Universidad Nacional Mayor de San Marcos, Lima; MUSA= Museo de Historia Natural, Universidad Nacional de San Agustín, Arequipa; ROM= Royal Ontario Museum, Toronto; USNM= National Museum of Natural History, Washington, D.C.

\section{Resultados Diversidad}

La diversidad de los mamíferos terrestres, acuáticos y marinos reportados para Perú alcanza a 13 órdenes, 50 familias, 218 géneros y 508 especies (Anexo 1); con lo cual, Perú es el tercer país con mayor diversidad de especies en el Nuevo Mundo, ubicándose después de Brasil y México (Tabla 1). Es además el quinto país más diverso a nivel mundial de acuerdo a los resultados de la IUCN et al. (2008). Los mamíferos del Perú incluyen 40 didelfimorfos, 2 paucituberculados, 1 sirenio, 6 cingulados, 7 pilosos, 39 primates, 162 roedores, 1 lagomorfo, 2 soricomorfos, 165 quirópteros, 34 carnívoros, 2 perisodáctilos y 47 cetartiodáctilos (Tabla 2). Casi las dos terceras partes de esta diversidad (327 especies, 64\%) están compuestas por los roedores y murciélagos. 
Tabla 1. Diversidad de mamíferos de Perú comparado a otros países de la región Neotropical y el Mundo.

\begin{tabular}{|c|c|c|c|c|c|c|c|}
\hline País & $\frac{\tilde{D}}{\tilde{D}}$ & 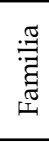 & 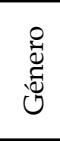 & 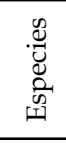 & 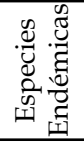 & ১e & 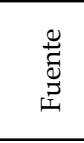 \\
\hline Guyana & 10 & 36 & 130 & 226 & 0 & 0.0 & 1 \\
\hline Venezuela & 10 & 39 & 158 & 325 & 11 & 3.4 & 2,3 \\
\hline Colombia & 15 & 46 & 196 & 434 & 28 & 6.5 & 4,5 \\
\hline Ecuador & 14 & 44 & 176 & 382 & 38 & 9.9 & 6 \\
\hline Perú & 13 & 50 & 218 & 508 & 65 & 12.8 & 7 \\
\hline Brasil & 12 & 46 & - & 652 & 158 & 24.2 & 8,9 \\
\hline Bolivia & 11 & 43 & 179 & 366 & 17 & 4.6 & 10,11 \\
\hline Chile & 9 & 28 & 85 & 155 & 17 & 11.0 & 12,13 \\
\hline Argentina & 13 & 47 & 181 & 386 & - & 0.0 & 14 \\
\hline Uruguay & 7 & 29 & 83 & 112 & 1 & 0.9 & 15 \\
\hline Paraguay & 9 & 30 & 105 & 156 & 2 & 1.3 & 16 \\
\hline México & 12 & 47 & 192 & 529 & 160 & 30.2 & 17 \\
\hline Mundo & & & & 5421 & & & 18,19 \\
\hline
\end{tabular}

1= Engstrom y Lim (2002), 2 = Ceballos et al. (2002), 3 = Soriano y Ochoa (1997), 4 = Alberico y Rojas-Díaz (2002), 5 = Alberico et al.(2000), 6 = Tirira (2007), $7=$ presente trabajo, $8=$ Reis et al. (2006), $9=$ Alho et al. (2002), $10=$ Salazar Bravo et al. (2002, 2003), $11=$ Tarifa (2005), $12=$ Muñoz Pedreros y Yáñez Valenzuela (2000), $13=$ Mella et al. (2002), $14=$ Barquez et al. (2006), 15 = González (2001), 16 = Myers et al. (2002), 17 = Ceballos et al. (2002, 2005), 18 = Wilson y Reeder (2005), 19 = Reeder et al. (2007)

A escala ecorregional, las especies de mamíferos son conspicuamente más diversas en la Selva Baja (292) y Yungas (210), seguidas por un grupo de ecorregiones moderadamente diversas: Bosque Tropical del Pacífico (65), Serranía Esteparia (63), Puna (63), Bosque Seco Ecuatorial (60), Sabana de Palmera (60) y

Tabla 2. Diversidad y endemismo de los mamíferos del Perú por categorías taxonómicas.

\begin{tabular}{|c|c|c|c|c|c|c|}
\hline Orden & 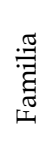 & 蓠 & 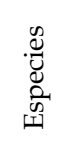 & 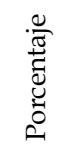 & 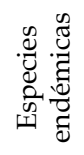 & 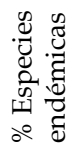 \\
\hline Didelphimorphia & 1 & 14 & 40 & 7,9 & 8 & 1,6 \\
\hline Paucituberculata & 1 & 2 & 2 & 0,4 & 0 & 0,0 \\
\hline Sirenia & 1 & 1 & 1 & 0,2 & 0 & 0,0 \\
\hline Cingulata & 1 & 3 & 6 & 1,2 & 1 & 0,2 \\
\hline Pilosa & 4 & 5 & 7 & 1,4 & 0 & 0,0 \\
\hline Primates & 3 & 12 & 39 & 7,7 & 3 & 0,6 \\
\hline Rodentia & 11 & 63 & 162 & 31,9 & 45 & 8,9 \\
\hline Lagomorpha & 1 & 1 & 1 & 0,2 & 0 & 0,0 \\
\hline Soricomorpha & 1 & 1 & 2 & 0,4 & 1 & 0,2 \\
\hline Chiroptera & 8 & 63 & 165 & 32,5 & 7 & 1,4 \\
\hline Carnivora & 7 & 21 & 34 & 6,7 & 0 & 0,0 \\
\hline Perissodactyla & 1 & 1 & 2 & 0,4 & 0 & 0,0 \\
\hline \multirow[t]{2}{*}{ Cetartiodactyla } & 10 & 31 & 47 & 9,3 & 0 & 0,0 \\
\hline & 50 & 218 & 508 & & 65 & 12,8 \\
\hline
\end{tabular}

Tabla 3. Distribución de especies de mamíferos de Perú por ecorregiones (según Brack-Egg, 1986).

\begin{tabular}{|c|c|c|c|c|}
\hline Ecorregión & 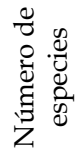 & 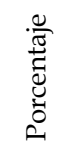 & 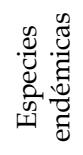 & 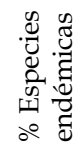 \\
\hline Oceánica & 30 & 5,9 & 0 & 0,0 \\
\hline BT Pacífico & 65 & 12,8 & 0 & 0,0 \\
\hline BS Ecuatorial & 60 & 11,8 & 3 & 4,6 \\
\hline Desierto & 46 & 9,1 & 6 & 9,2 \\
\hline Serrania Esteparia & 63 & 12,4 & 12 & 18,5 \\
\hline Páramo & 23 & 4,5 & 4 & 6,2 \\
\hline Puna & 63 & 12,4 & 10 & 15,4 \\
\hline Yungas & 210 & 41,3 & 39 & 60,0 \\
\hline Selva Baja & 292 & 57,5 & 14 & 21,5 \\
\hline Sabana de Palmera & 60 & 11,8 & 1 & 1,5 \\
\hline
\end{tabular}

Desierto (46). La Oceánica (30) y el Páramo (23) son las regiones menos diversas (Tabla 3).

Adicional a la fauna nativa se reconocen 15 especies introducidas, la mayoría de ellas domésticas, siguiendo la nomenclatura propuesta por Gentry et al. (2004) (Tabla 4).

\section{Notas taxonómicas y nuevos registros}

Se presenta un comentario taxonómico para aquellas especies cuya taxonomía no concuerda con Wilson y Reeder (2005) y/o Gardner (2008), o cuando son registros nuevos para el país:

Tabla 4. Lista de mamíferos introducidos al Perú.

\begin{tabular}{ll}
\hline Nombre científico & Nombre común \\
\hline Carnivora & \\
Canidae & \\
Canis familiaris Linnaeus & Perro \\
Felidae & \\
Felis catus Linnaeus & Gato \\
Perissodactyla & \\
Equidae &
\end{tabular}

Equus asinus Linnaeus

Equus caballus Linnaeus

Burro, asno

Cetartiodactyla

Bovidae

Bos taurus Linnaeus

Capra hircus Linnaeus

Ovis aries Linnaeus

Bubalus bubalis Linnaeus

Camelidae

Camelus dromedarius Linnaeus

Suidae

Sus domesticus Erxleben Cerdo, chancho, cuche

Lagomorpha

Leporidae

Lepus europaeus Pallas Liebre, liebre europea

Oryctolagus cuniculus Linnaeus Conejo

Rodentia

Muridae

Rattus rattus (Linnaeus) Rata negra

Rattus norvegicus (Berkenhout) Rata gris

Mus musculus (Linnaeus) Ratón, pericote 


\section{DideLPHIMORPHIA}

\section{Didelphis marsupialis Linnaeus, 1758}

La presencia de Didelphis albiventris en el Perú necesita ser evaluada y requiere una mayor sustentación. Diaz y Willig (2004) ampliaron el rango de distribución de Didelphis albiventris hasta el noreste de Perú, basado en un espécimen (MMD 2841) colectado en Ninarumi, carretera Iquitos-Nauta, Loreto. Sin embargo, Cerqueira y Tribe (2008) no reportan albiventris para el Perú ni discuten el reporte de Diaz y Willig (2004), y mas bien comentan que el registro de Brown (2004) del río Samiria, Loreto, se debió a que la autora no diferenció entre especies del complejo D. albiventris. Nuestro examen del espécimen MMD 2841 indica que es un ejemplar inmaduro de edad II (según Kajin et al. 2008), que tiene los extremos de la oreja blancos. No obstante, este ejemplar es determinado aquí como D. marsupialis por tener una línea frontal media tenue, cola con una escasa pilosidad en la base y con más de la mitad distal blanca, además de la ausencia de cerdas blancas entremezcladas con el pelaje negruzco; características que no coinciden con las propuestas para D. albiventris (Cerqueira y Tribe 2008, Teta y de Tommaso 2009). Las orejas son ciertamente blanquecinas con la base negra; sin embargo, se observan manchas oscuras en la porción blanquecina que sugieren una progresiva pigmentación. Esta coloración es sin embargo variable ya que ejemplares inmaduros y subadultos de $D$. marsupialis pueden tener la punta de las orejas blanca o rosado pálida (Cerqueira y Tribe 2008).

\section{Gracilinanus aceramarcae (Tate, 1931)}

La presencia de esta comadrejita en Perú está sustentada por un ejemplar de Puno, Agualani, kilometro 9 norte de Limbani (MVZ 171411) (Pacheco et al. 1995, Voss et al. 2005); y otros ejemplares de Cusco, Paucartambo (Solari et al. 2006) y Cordillera Vilcabamba (Voss et al. 2005). Actualmente, su distribución se extiende hasta el norte, en Piura, Huancabamba, El Carmen de la Frontera, 3176 m (MUSM 23381) a lo largo de las Yungas. Sin embargo, una revisión detallada sugiere la presencia de más de una especie.

\section{Gracilinanus emiliae (Thomas, 1909)}

Comadrejita reportada para Perú, en base a un espécimen cerca de la localidad de Nuevo San Juan, en el río Gálvez, tributario del río Yavarí, departamento de Loreto por Voss et al. (en prensa).

\section{Lutreolina crassicaudata (Desmarest, 1804)}

Luna et al. (2002) reportaron por primera vez la especie para Perú, en base a un ejemplar proveniente del departamento de Madre de Dios, Tambopata, S.N. Pampas del Heath, Refugio Juliaca; $12^{\circ} 57,4^{\prime} S ; 68^{\circ} 52,9^{\prime} \mathrm{W}$ (MUSM 11647). Gardner (2005) y Stein y Patton (2008) no incluyeron este registro.

\section{Marmosa (Micoureus) phaea Thomas, 1899}

Gardner y Creighton (2008) mencionan la probable ocurrencia de esta especie en el departamento de Tumbes, Perú. Se confirma aquí su presencia en base a especímenes colectados en la quebrada Faical y Campo Verde, departamento de Tumbes (MUSM 24483--24486; MUSA 421--424, 455) (Pacheco et al. 2008a). La especie se asigna al género Marmosa siguiendo la última revisión de Voss y Jansa (2009), quienes consideran Micoureus como un subgénero.

\section{Monodelphis handleyi Solari, 2007}

Especie recientemente descrita por Solari (2007) en base al ejemplar tipo (MUSM 15991) y siete paratipos colectados en el Centro de Investigaciones Jenaro Herrera, kilometro 2,8 este de Jenaro Herrera, margen oriental del río Ucayali, provincia de Requena, departamento de Loreto.

\section{Monodelphis sp.}

Una nueva especie de Monodelphis de tres bandas dorsales de las Yungas centrales de Perú, sustentada en base a varios ejemplares de Huánuco, Pasco, Junín y Cusco (MUSM 11334, 18943, 13007, 14631 respectivamente) (Solari et al. en preparación); y listada previamente como especie nueva (Emmons et al. 2001, Solari et al. 2001, Voss y Jansa 2003).

\section{Philander opossum (Linnaeus, 1758)}

La zarigüeyita Philander olrogi Flores, Barquez y Díaz, 2008 fue recientemente descrita y diferenciada de $P$. opossum en base a características externas y morfometría (Flores et al. 2008). El registro de Perú estuvo basado en el espécimen MMD 3865 de Paujil, oeste del kilometro 37,4 de la carretera Iquitos-Nauta, provincia Maynas, Loreto; sin embargo, este ejemplar es aquí determinado como P. opossum en base al rostro proporcionalmente largo y poco robusto. En un plot bivariado, las medidas de este ejemplar (ancho nasal a nivel de la sutura frontomaxilar, BN2 $=9,5$ versus la longitud occipitonasal, $\mathrm{ONL}=73,9)$ se agrupan con otros P. opossum en lugar de los P. olrogi de Bolivia (basado en Flores et al. 2008: Tabla 1 y Fig. 4). Además la forma del rostro de este ejemplar cae en un rango de variaciones encontradas para otros $P$. opossum de la zona de Iquitos.

\section{Thylamys sp.}

Una especie nueva de marmosa coligruesa presente en la vertiente occidental del sur del Perú y diferenciada de T. pallidior (Palma et al. en preparación). Thylamys sp. se distribuye desde el sur de Lima, en la zona de Yauyos (MUSA 5167, 5194) hasta Omate en Moquegua (MUSA 1410).

\section{Primates}

\section{Saguinus fuscicollis (Spix, 1823)}

Aquino y Encarnación (1994) reconocen seis subespecies del pichico común para Perú. Adicionalmente, Saguinus fuscicollis melanoleucus (Miranda Ribeiro 1912) fue recientemente reportada en las cabeceras del río Breu y la quebrada Beu cerca de la frontera con Brasil, distrito de Yurúa, departamento de Ucayali (Mena et al. 2007). Aunque Groves (2001, 2005) eleva melanoleucus a especie plena, se sigue aquí a Peres et al. (1996). Estos autores no apoyan la separación de melanoleucus a especie ya que demuestran la existencia de flujo génico con fuscicollis en la cabecera del río Juruá, Brasil.

\section{Cebus libidinosus Spix, 1823}

Groves (2001) reconoce esta especie con cuatro subespecies: libidinosus Spix, 1823; pallidus Gray, 1866; paraguayanus Fischer, 1829; y juruanus Lönnberg, 1939. Rylands et al. (2005) sigue 
a Lönnberg (1939) al incluir pallidus como una subespecie de libidinosus. Aquino y Encarnación (1994) lo reportan como Cebus apella pallidus para el sureste del Perú, al sur de los ríos Madre de Dios e Inambari en los departamentos de Puno y Madre de Dios, pero Groves (2005) no lo incluye para Perú. Aquí es tentativamente aceptada teniendo en cuenta la falta de documentación con especímenes.

\section{Callicebus aureipalatii Wallace, Gómez, A. Felton y A. M. Felton, 2006}

Wallace et al. (2006) describieron recientemente esta especie para el noroeste de Bolivia y predijeron que podría llegar hasta el borde sur del río Madre de Dios, en Perú. Wallace et al. (2008) confirman recientemente que estaría al menos hasta el río Tambopata, al sur de Perú.

\section{Callicebus brunneus (Wagner, 1842)}

Van Roosmalen et al. (2002) proveen la última revisión del género Callicebus, donde indican que $C$. dubius Herhkovitz, 1988 se distribuye hasta el Perú al este del río Las Piedras, en Madre de Dios; lo cual es aceptado por Groves (2005). Sin embargo, Wallace et al. (2006) dudan de la validez de dubius y sugieren que la distribución de dubius, brunneus y cupreus debe ser revisada; opinión que es seguida aquí.

\section{Callicebus lucifer Thomas, 1914}

El tocón de collar Callicebus torquatus conocido previamente como única especie en el grupo torquatus (Hershkovitz 1990, Aquino y Encarnación 1994, Groves 2001) fue dividida en seis especies (torquatus, lugens, lucifer, purinus, regulus y medemi) por van Roosmalen et al. (2002). Según estos autores y Groves (2005), C. lucifer es la especie presente en el Perú. Se anota que estudios posteriores aún usan el nombre torquatus sin proveer una discusión taxonómica (Aquino et al. 2008). Esta especie, al igual que el género, requiere de una moderna revisión taxonómica que, además de patrones de coloración, empleen comparaciones de morfología cráneo dental, cariotipos y secuencia molecular, entre otros caracteres.

\section{Alouatta juara Elliot, 1910}

Según Groves $(2001,2005)$ las especies de Alouatta presentes en el Perú son $A$. sara y $A$. seniculus; la última con $A$. s. juara como subespecie (y puruensis como sinónimo). Sin embargo, Gregorin (2006) reconoce como especies plenas a $A$. juara y A. puruensis y ambas distribuidas en el centro y suroriente de Perú, respectivamente. No obstante este avance, la situación de las especies de Alouatta para Perú es confusa ya que no está resuelto el estado y distribución de sara y seniculus para Perú. $\mathrm{Al}$ aceptarse a $A$. juara es necesario rechazar a $A$. seniculus como presente para Perú, al menos para el sur del río Amazonas. Además de $A$. juara, se aceptan aquí tentativamente a $A$. puruensis y $A$. sara; pero urge una exhaustiva revisión de las poblaciones peruanas de Alouatta.

\section{Alouatta palliata (Gray, 1849)}

Groves (2005) no incluye esta especie para Perú. Sin embargo, su presencia en Tumbes, está documentada en varios trabajos (Pulido y Yockteng 1986, Aquino y Encarnación 1994) y observaciones recientes (V. Pacheco, com. pers.).

\section{Lagothrix flavicauda (Humboldt, 1812)}

Groves (2001) resucitó el género Oreonax para flavicauda al encontrarlo más relacionado a Ateles que a las especies de Lagothrix. Matthews y Rosenberger (2008) sostienen que esta ubicación fue un resultado espurio debido al limitado número de taxones y sugieren mantener Lagothrix flavicauda. Estos autores realizaron un análisis de parsimonia de 14 atelinos con caracteres morfológicos basados en Groves (2001), encontrando en un consenso por mayoría a $L$. flavicauda relacionado a otras especies de Ateles (Matthews y Rosenberger 2008: fig. 5). Aunque este árbol soporta a Groves (2001), ellos concluyen que este resultado es poco robusto. Por otro lado, Matthews y Rosenberger (2008) no proveen una filogenia que demuestre que flavicauda forma un grupo natural con las otras especies de Lagothrix, y que soporte su decisión de incluirlo en este género. Nosotros mantenemos Lagothrix flavicauda en base a los resultados de Paredes (2003) quien realizó un análisis cladístico de Lagothrix usando 54 caracteres morfológicos, donde encuentra a flavicauda formando un clado monofilético con otras cuatro especies de Lagothrix.

\section{RODENTIA}

\section{Microsciurus sp.}

Esta ardilla, de tamaño mediano, fue incluida en la lista de Pacheco et al. (1995) en el género Microsciurus, basado en cuatro ejemplares (MUSM 7920_7922 y 7971) del Parque Nacional Río Abiseo, departamento de San Martín. El rango de medidas externas de estos ejemplares son: LT 343-363; LC 153-158; LP 45-52; LO 20-25 y Peso 212-244 g. Estas medidas, más el CBL 41,05—41,70 y ML 8,72—9,02, indican que son notablemente más grandes que $M$. flaviventer. Diferenciándose también de esta especie por el pelaje marrón, con el extremo distal de los pelos anaranjados; los nasales comparativamente largos y con los bordes posteriores alineados con los premaxilares; y los incisivos con o sin surco, proodontes o ortodontes.

\section{Akodon surdus Thomas, 1917}

Actualmente aceptado como especie válida (Musser y Carleton 2005); pero requiere de un mayor sustento para diferenciarlo de A. aerosus. Smith y Patton (2007) argumentan que aunque no hay datos genéticos de esta especie, pertenece probablemente al grupo aerosus, como una especie distinta o tal vez conespecífica con aerosus.

\section{Cerradomys maracajuensis (Langguth y Bonvicino, 2002)}

Reportado por Emmons et al. (1994) para Pampas del Heath, departamento de Madre de Dios, como Oryzomys buccinatus; y reidentificado después como Oryzomys subflavus (Emmons et al., 2002). Después que Weksler et al. (2006) erigieran el género Cerradomys para el grupo subflavus, la nomenclatura fue recientemente revisada por Percequillo et al. (2008); quienes asignaron el nombre maracajuensis para el registro de Perú, departamento de Puno, río Heath, Aguas Claras (USNM 579688). Sin embargo, esta localidad corresponde al departamento de Madre de Dios.

\section{Eligmodontia hirtipes (Thomas, 1902)}

Musser y Carleton (2005) reconocen a E. puerulus (Philippi, 1896) como distribuida en el sur del Perú. Sin embargo, en 
base a evidencia cariotípica, E. puerulus $(2 \mathrm{n}=32-34, \mathrm{NF}=$ 48) es restringida para la región de puna de Chile, noroeste de Argentina y se desconoce su posible presencia en Perú (Lanzone y Ojeda 2005); mientras que el cariotipo $2 \mathrm{~N}=50, \mathrm{NF}=48$ es asignado a E. hirtipes (Spotorno et al. 2001). Ambos taxa son también diferenciados en las secuencias del gen de citocromo- $b$ (Lanzone et al. 2007, Mares et al. 2008). Más temprano, Pearson y Patton (1976) reportaron el cariotipo $2 \mathrm{~N}=50$ para una población de Ancomarca, departamento de Puno y Challapalca, departamento de Tacna, pero con el nombre de E. typus Cuvier. Estos especímenes, más registros adicionales de Pampa de Ancomarca (MUSM 2322), la laguna Loriscota y Caccachara en Puno (MUSA 4432, 4446), laguna Blanca en Tacna (MUSA 3235, 3429-32) y Chilota en Moquegua (MUSA 815-18) son asignados aquí a $E$. hirtipes.

\section{Eremoryzomys polius (Osgood, 1913)}

Especie endémica del departamento Amazonas, al este del río Marañón. Weksler et al. (2006) erigieron el género Eremoryzomys para el grupo polius.

\section{Euryoryzomys macconnelli (Thomas, 1910)}

Weksler et al. (2006) crean el género Euryoryzomys para el grupo que contiene macconnelli y nitidus.

\section{Hylaeamys perenensis (J. A. Allen, 1901)}

Weksler et al. (2006) establecen el género Hylaeamys para el clado que contiene perenensis y yunganus.

\section{Melanomys caliginosus (Tomes, 1860)}

Rodríguez (1998) reporta a Akodon mollis en la quebrada Naranjal, departamento de Tumbes, basados en los especímenes (MUSA 425, 444). Sin embargo, estos especímenes son aquí determinados como Melanomys caliginosus, siendo el primer reporte para el país de la especie. Recientemente, Hanson y Bradley (2008) sugieren que $M$. caliginosus es un complejo de al menos cuatro especies, obligando a un análisis más detallado, morfológico y molecular, de la población peruana.

\section{Melanomys robustulus Thomas, 1914}

Esta especie fue reportada por Thomas (1914) para Gualaquiza, oriente de Ecuador y fue considerada restringida al sureste de Ecuador (Musser y Carleton 2005). Se reporta aquí la especie para Perú en base a tres ejemplares (AMNH 71552, 71554, 71555 ), colectados por Olalla e hijos en 1925, provenientes de la boca del río Curaray, afluente del río Napo, departamento de Loreto.

\section{Necromys amoenus (Thomas, 1900)}

Actualmente una sola especie. Sin embargo, D' Elia et al. (2008) encuentran un rango de divergencia genética entre 7,75 a $10,9 \%$ entre las poblaciones del sur de Perú y el centro de Bolivia con el noroeste de Argentina, concluyendo que este taxon puede estar conformada por más de una especie.

\section{Necromys lenguarum (Thomas, 1898)}

Reportado para Perú como Bolomys lasiurus (Lund 1841) por Pacheco et al. (1995) y Emmons et al. (2002) basados en ejem- plares de Pampa del Heath, Madre de Dios. Registros adicionales (MUSM 21824, 21825) provienen de La Cachuela, Madre de Dios (12³1'04,3"S; 69¹0'18,8"W). Asignación de estas poblaciones a $N$. lenguarum es tentativo, basado en la diferenciación genética entre $N$. lasiurus y $N$. lenguarum reportada por D'Elía et al. (2008) y la asignación de las poblaciones de Bolivia a $N$. lenguarum por estos autores.

\section{Nectomys rattus (Pelzeln, 1883)}

Gardner y Patton (1976) reportan el cariotipo variante 1 de Nectomys squamipes (Brants) con $2 \mathrm{~N}=52$ y FN= 52 de Yarinacocha, Loreto. Este cariotipo fue asignado a mattensis Thomas 1903 por Patton et al. (2000), mientras que para Voss et al. (2001) el nombre confiable más antiguo aplicado a dicho cariotipo sería melanius Thomas, 1910. Musser y Carleton (2005) finalmente optan por rattus Pelzeln, 1883 como el nombre más antiguo basado en la información del tipo proporcionado por Voss et al. (2001).

\section{Nephelomys albigularis (Tomes, 1860)}

Weksler et al. (2006) erigieron el género Nephelomys para el grupo albigularis, representado en Perú por albigularis, auriventer, keaysi y levipes.

\section{Oreoryzomys balneator (Thomas, 1900)}

Weksler et al. (2006) formaron el género Oreoryzomys para el grupo balneator e incluyen el registro de Cajamarca, $4 \mathrm{~km}$ Oeste de Chaupe, basado en los especímenes AMNH 268134-5, 268139, 268141 y 268143. Otros registros para Perú provienen de Piura, Huancabamba, Carmen de la Frontera, Alto Samaniego (MUSM 18200) y quebrada El Gallo (MUSM 23553), confirmando su presencia en las yungas orientales del norte del Perú.

\section{Phyllotis sp.}

Especie aún no descrita del departamento de La Libertad, Santiago de Chuco, Quiruvilca (MUSM 17243-17250). Diferenciada molecularmente de $P$. andium por secuencias mitocondriales y nucleares (Steppan et al. 2007).

\section{Transandinomys talamancae (J. A. Allen, 1891)}

Musser et al. (1998) indicaron que esta especie debería estar en Perú, lo que fue confirmado por Rodríguez (1998) en base a especímenes colectados en el departamento de Tumbes, Zarumilla, quebrada Los Naranjos (MUSM 10723, 10724, 10728). Sin embargo, este registro no fue incluído en Musser y Carleton (2005). Recientemente, Weksler et al. (2006) crean el género Transandinomys para el grupo talamancae.

\section{Echinoprocta rufescens Gray, 1865}

Este pequeño puerco espín de cola corta es conocido en los Andes de Colombia y vertientes orientales de los Andes de Ecuador (Alberico et al. 1999, Eisenberg y Redford 1999; Delgado y Tirira 2008) desde 800 a 3200 m. Recientemente, Williams (2008) reportó esta especie por primera vez para Perú, en base a un ejemplar de Lambayeque, Reserva Chaparrí, denominándola Echinoprocta nov. sp. Sin embargo, este ejemplar (MUSM 23114) es un juvenil que concuerda mayormente con las caracte- 
rísticas externas y craneales de E. rufescens de Colombia, Bogotá (ICN, FMNH) en detalle descritas por Alberico et al. (1999). Una revisión más detallada que incluye este y nuevos ejemplares se encuentra en preparación (V. Pacheco et al., com. pers.).

\section{Lagidium viscacia (Molina, 1782)}

Muñoz-Pedreros (2000) y Woods y Kilpatrick (2005) listan la especie para el sur del Perú. Al presente dos especímenes del Perú (no revisados por nosotros) son conocidos en colecciones, una a 100 millas al oeste de Puno (ROM 110435) y la segunda de El Tambo (departamento no precisado, USNM 304555). La distribución es entonces pobremente conocida; además, la definición de la especie y su delimitación con L. peruanum es imprecisa. La especie es tentativamente mantenida pendiente de una revisión exhaustiva.

\section{Cavia aperea Erxleben, 1777}

Emmons et al. (2002) reportaron esta especie para Pampas del Heath, departamento de Madre de Dios, basados en tres especímenes (MUSM 11743, 11744 y 11745); registro omitido por Woods y Kilpatrick (2005). Estos especímenes son diferenciables por el patrón de coloración y características craneales de las poblaciones asignadas a tschudii de la costa y Andes de Perú. C. aperea presenta el pelaje ventral más claro y el collar débil o nada prolongado hasta el mentón. Además, en el cráneo se observa que el rostro es más corto y la fosa mesopterygoidea es más ancha. Sin embargo, concurrimos con Woods y Kilpatrick (2005) en que el género necesita una revisión.

\section{Isothrix barbarabrownae Patterson y Velazco, 2006}

Una especie recientemente descrita por Patterson y Velazco (2006) en base a un espécimen (MUSM 16819) colectado en el kilometro 138,5 de la Carretera Paucartambo-Shintuya, cerca a "Suecia" (un restaurante de la carretera), 1900 m, Paucartambo, Cusco.

\section{Pattonomys occasius (Thomas, 1921)}

Una rara rata arborícola listada como Makalata occasius por Woods y Kilpatrick (2005). Emmons (2005) revisa los roedores echimyidos y fundamenta la distinción de la especie en el nuevo género Pattonomys.

\section{SORICOMORPHA}

\section{Cryptotis equatoris (Thomas, 1912)}

Esta musarańa está reportada para los Andes del centro y norte de Ecuador (Hutterer, 2005; Woodman y Péfaur, 2008). La especie es por primera vez registrada para Perú en base a un espécimen de Machete, carretera Zapalache-El Carmen, Piura (LSUMZ 26887); y otros provenientes de Huancabamba, El Carmen de la Frontera, Piura (MUSM 23452-58). El ejemplar LSUMZ fue determinado como $C$. peruviensis por Vivar et al. (1997), quienes remarcaron las diferencias entre este espécimen y el holotipo de peruviensis (MUSM 8373). Sin embargo, el registro de especímenes adicionales en Piura ha permitido entender estas diferencias y asignar a equatoris las poblaciones de Piura, quedando peruviensis restringido solo para el departamento de Cajamarca, Las Ashitas, 3150 m, ca. kilometros 42 al oeste de Jaén.

\section{Chiroptera}

\section{Anoura aequatoris Lönnberg, 1921}

Mantilla-Meluk y Baker (2006) elevan aequatoris a nivel de especie al diferenciarla morfológicamente de otras especies pequeñas de Anoura por presentar un denso fleco en el borde posterior del uropatagio. Aunque Griffith y Gardner (2008) no siguen esta propuesta debido a que es difícil diagnosticar el taxón y a la necesidad de una revisión del complejo caudifer, nosotros concurrimos en que aequatoris es una especie válida presente en las yungas del Perú. Especímenes adicionales con pelo denso en el uropatagio, asignados a esta especie, fueron colectados en Pasco, Oxapampa, San Alberto, P.N. Yanachaga Chemillén (MUSM 14915, 14916).

\section{Anoura fistulata Muchhala, Mena y Albuja, 2005}

Esta especie fue descrita y reportada para varias localidades de Ecuador (Muchhala et al. 2005) y Colombia (Mantilla-Meluk y Baker 2008). Recientemente, fue reportada para Perú por Jiménez et al. (2008), basado en un ejemplar proveniente del río Playa Colorada, distrito de Huicungo, San Martín, 1704 m (MUSM 24363). Una revisión en progreso (V. Pacheco y R. Cadenillas, com. pers.) muestra que la especie se encuentra también en el río Abiseo, San Martín (MUSM 7213, 7215) y probablemente más al sur a lo largo de los Andes.

\section{Lonchophylla pattoni Woodman y Timm, 2006}

Especie descrita recientemente por Woodman y Timm (2006) en base a un único ejemplar de la Reserva Cuzco Amazónico (ca. 12³3'S, 6903'W), departamento de Madre de Dios (KU 144232). Este ejemplar actualmente se haya depositado como MUSM 24350.

\section{Glyphonycteris sylvestris Thomas, 1896}

Williams y Genoways (2008) incluyen a Glyphonycteris behnii (Peters, 1865) para Perú basado en el registro de dos especímenes de Cusco, río Cosńipata por Andersen (1906). Sin embargo, nosotros seguimos a Simmons (1996) y Simmons y Voss (1998: 61), quienes examinaron los especímenes de Cusco resolviendo que estos especímenes tienen un antebrazo de $40 \_42 \mathrm{~mm}$ y la morfología del incisivo superior esperada para G. sylvestris.

\section{Phyllostomus latifolius (Thomas, 1901)}

Tello et al. (2008) registran la especie por primera vez para Perú en base a cuatro especímenes (MUSM 21214-21217) capturados en las cuevas de Huaconqui a 12 kilometros al sur del Puesto de Vigilancia Arcadia, río Napo, distrito de Torres Causana, Maynas, Loreto. Estos ejemplares tienen el calcar más grande que el pie, el antebrazo menor a $61 \mathrm{~mm}$, tibia menor a $24 \mathrm{~mm}$ y el cráneo menor a $29 \mathrm{~mm}$; concordantes con la descripción de Williams y Genoways (2008).

\section{Artibeus ravus (Miller, 1902)}

Según Marques-Aguilar (2008), Artibeus phaeotis (Miller, 1902) cuya localidad tipo es Yucatán, México, incluye como sinónimo junior a ravus cuya localidad tipo es de Esmeraldas, Ecuador. Definido así, phaeotis se distribuye desde México, Centro América y noroeste de Sudamérica hasta el sur de Ecuador. Sin embargo, 
estudios recientes empleando secuencias del gen citocromo- $b$, demuestran que phaeotis, representado por especímenes de México, Nicaragua, Honduras y Ecuador, no es monofilético (Hoofer et al. 2008, Redondo et al. 2008); motivo por el cual ravus, representado por especímenes de Esmeraldas y Guayas, es reconocida como especie plena (Hoofer et al. 2008). Recientemente, Pacheco et al. (2007a) reportaron Dermanura sp. de la quebrada Naranjos y quebrada Campo Verde, departamento de Tumbes. Este es aquí determinado como $A$. ravus, por presentar el borde blanquecino de la oreja y el paladar con pequeños forámenes, coincidentes con los caracteres mencionados por Miller (1902); y por la proximidad con las poblaciones de Ecuador analizadas por Hoofer et al. (2008). Nuestros especímenes son el primer registro para Perú.

\section{Platyrrhinus incarum (Thomas, 1912)}

Velazco y Patterson (2008) elevan incarum a nivel de especie y mencionan que se encuentra en la cuenca amazónica, mientras que $P$. helleri se restringe a Centroamérica.

\section{Cynomops greenhalli Goodwin, 1958}

Eger (2008) no incluye la especie para Perú en la última síntesis del género. Pero es recientemente reportada para el Perú en base a dos especímenes (MUSM 24469, 24470) de la quebrada Faical, Pampas de Hospital, Tumbes (Pacheco et al. 2008a). Se determina la especie en base a la tercera comisura de la $\mathrm{m} 3$ reducida, las fosas del basiesfenoide ausentes o poco desarrolladas, el antebrazo mayor a $37 \mathrm{~mm}$ y la longitud cóndilo basal mayor a $18 \mathrm{~mm}$, coincidentes con las características descritas por Eger (2008).

\section{Eumops maurus (Thomas, 1901)}

Best et al. (2001) y Simmons (2005) no incluyen esta especie para Perú; a pesar del reporte de Luna et al. (2002) quienes la reportan para Pampas del Heath, Madre de Dios, basados en tres especímenes (MUSM 11668-11670). Nuestro examen de estos especímenes confirman la determinación de $E$. maurus como tal por el color marrón chocolate del pelaje y la franja blanca ventral de aproximadamente $20 \mathrm{~mm}$ de longitud, consideradas en la diagnosis de la especie elaborada por Sodré et al. (2008), así como la medida promedio de antebrazo de los tres ejemplares $(54,2 \mathrm{~mm})$. Estos especímenes fueron colectados en un área periódicamente inundable dominada por palmeras que concuerda además con los hábitats mencionados por Sodré et al. (2008) y Eger (2008).

\section{Eumops wilsoni Baker, McDonough, Swier, Larsen, Carrera y Ammerman, 2009}

Especie del complejo glaucinus recientemente descrita en base a ejemplares del occidente de Ecuador y noroeste de Perú (Baker et al. 2009). Estos autores restringen E. glaucinus en Sudamérica al este de los Andes, aparentemente no hay registro conocido de esta especie para Perú.

\section{Promops nasutus (Spix, 1823)}

Emmons et al. (2002) reportan esta especie para las Pampas del Heath, departamento de Madre de Dios, basados en 10 especímenes (MUSM 11693-11702); registro que no fue mencionado o discutido por Eger (2008). Nuestro examen de estos especímenes muestran las siguientes medidas promedios: longitud total del cráneo $(\mathrm{LTC}=19,65 \mathrm{~mm})$ y antebrazo $(\mathrm{AB}=$ $52,1 \mathrm{~mm}$ ); las cuales no coinciden con lo reportado para $P$. nasutus (Eger 2008, Gregorin y Taddei 2002). Según estos autores, $P$. nasutus tiene un LTC menor a $19,1 \mathrm{~mm}$ y AB menor a 50 $\mathrm{mm}$. Por lo tanto estos especímenes son determinados como $P$. centralis, concordando con la distribución de la especie (Eger 2008). Sin embargo, la especie es mantenida tentativamente para Perú en base a dos especímenes provenientes de Lima y Piura (MUSM 229, 754), los cuales tienen las siguientes medidas $(\mathrm{LTC}=18,34 ; 18,36, \mathrm{y} \mathrm{AB}=47 ; 50)$; que concuerdan con lo reportado por Gregorin y Taddei (2002) y Eger (2008) para $P$. nasutus. Además, estos ejemplares presentan la base del pelaje dorsal más pálido que las poblaciones de $P$. centralis del lado oriental del Perú. Las poblaciones de la costa de Perú y Ecuador fueron descritas inicialmente como P. davisoni Thomas, 1921, taxón sinonimizado a $P$. centralis por Eger (2008) sin justificación. Considerando que el género necesita una revisión moderna, tentativamente seguimos a Genoways y Williams (1979) quienes consideraron que $P$. davisoni sería un sinónimo o subespecie de $P$. nasutus.

\section{Eptesicus furinalis (d'Orbigny, 1847)}

Este murciélago fue reportado para Perú, en el Santuario Nacional Pampas del Heath, Madre de Dios (Romo et al. 2002); registro no incluido por Davis y Gardner (2008). Nosotros confirmamos la presencia de la especie en base al espécimen (MUSM 11666) que presenta las siguientes medidas: $39 \mathrm{~mm}$ de antebrazo, 15,79 mm de longitud mayor del cráneo y 5,81 mm de hilera dental maxilar; que concuerdan con la descripción de Davis y Gardner (2008). Además, el pelaje dorsal marrón con las punta de los pelos claras la diferencia de E. brasiliensis.

\section{Rhogeessa velilla (Thomas, 1903)}

Pacheco et al. (2007a) reportaron el primer registro de la especie para Perú como $R$. io, basados en especímenes colectados en Tumbes, Zarumilla; siguiendo las características propuestas por Genoways y Baker (1996), LaVal (1973) y Vonhof (2000). Recientemente, Baird et al. $(2008,2009)$ reportaron que la población de Ecuador, Guayas e Isla Puná, presenta un cariotipo $(2 \mathrm{n}=42)$ diferente a $R$. io $(2 \mathrm{n}=30)$, por lo que elevan velilla a especie plena. Aunque las muestras de Tumbes carecen de cariotipo, son asignadas tentativamente a $R$. velilla por la ausencia de la cresta prominente o "helmet" formada por la cresta sagital y la occipital (Baird et al. 2008); y por la cercanía a las poblaciones de Ecuador (Genoways y Baker 1996).

\section{Carnivora}

\section{Lycalopex griseus (Gray 1837)}

Grimwood (1969) reporta esta especie para Perú como Dusicyon griseus, basado en la existencia de ejemplares de Arequipa, cerca a Camaná (MUSM 407), con caracteres diferenciables al zorro de Sechura; asimismo Pearson y Pearson (1978) reportan esta especie en las lomas de Tacna. Luego, Pacheco et al. (1995) y Zeballos et al. (2000) listan esta especie como Pseudalopex griseus. Quintana et al. (2000) mencionan que en el sur de Perú y norte de Chile la subespecie de este zorro corresponde a $P$. griseus domeykoanus. Más tarde Zeballos Patrón et al. (2002) listan la 
especie para Arequipa como Lycalopex gymnocercus siguiendo a Zunino et al. (1995), quienes sostienen que los zorros grises gymnocercus y griseus de Argentina son conespecíficos, por lo que proponen usar el nombre más antiguo gymnocercus.

La sistemática de este pequeño zorro gris está sin embargo lejos de estar resuelta. González del Solar y Rau (2004) y Lucherini et al. (2004) consideran a griseus y gymnocercus como dos especies distintas en el género Pseudalopex. Y los primeros autores consideran domeykoanus como subespecie de P. griseus. La evidencia molecular soporta también la distinción de ambas especies (Wayne et al. 1997, Zrzavý y Řičánková 2004). Con respecto al nombre genérico concordamos con Zunino et al. (1995) en el uso de Lycalopex Burmeister, 1854 por ser más antiguo que Pseudalopex Burmeister, 1856.

La presencia de esta especie en Perú está confirmado por varios ejemplares (MUSM 407; MUSA 242, 1650, 5905-06; MVZ $116316,121174,121175,139511,141627)$, con un rango de distribución desde Lima, San Bartolo hasta Tacna, Morro Sama. Los especímenes examinados (MUSM, MUSA) difieren en coloración y morfología craneal de $L$. culpaeus y L. sechurae (E. Vivar, com. pers.).

\section{Arctocephalus australis (Zimmermann, 1783)}

Es un lobo marino ampliamente distribuido en la costa Atlántica y del Pacífico de Sudamérica. Sin embargo, recientes estudios revelan una pronunciada variación morfológica y genética entre la población de Punta San Juan (Perú) y Rio Grande do Sul (sur de Brasil) (de Oliveira et al. 2008). Los autores concluyen que ambas poblaciones son distintas y representarían unidades evolutivas significativas ("Evolutionary Significant Units"). Dado que la localidad tipo de la especie se encuentra en las Islas Falkland, la población peruana podría ameritar un nuevo nombre. Sin embargo, se sugiere se la diferencie morfológica y genéticamente de otras especies presentes en el Océano Pacífico como A. galapagoensis Heller, 1904 y A. philippii (Peters, 1866).

\section{Nasuella olivacea (Gray, 1865)}

Esta especie es conocida de los hábitats montanos de Venezuela occidental, Colombia hasta Ecuador central (Eisenberg y Redford 1999, Reid y Helgen 2008) y fue reportada para Apurímac, Perú, por Pacheco et al. (2008b).

El reporte del coatí andino o capiso está sustentado en dos especímenes (MUSM 17029 y 17030); el primero proveniente de Apurímac, Abancay, Huanipaca y el segundo de Cusco, La Convención, Vilcabamba, Pacaypata, 2200 m; ambos colectados por P. Hocking. Estos especímenes presentan el nasal delgado y alargado, la cresta sagital casi ausente, el pelaje dorsal largo y de coloración marrón verdoso con una banda media dorsal más oscura que se prolonga hacia la nuca, el pelaje dorsal de los brazos y por encima de los ojos es grisáceo, las orejas son cortas con los bordes blanquecinos, la coloración de la región ventral crema y las patas negruzcas; características que coinciden con lo reportado por Martínez (2004) y Jarrín (2001). Estos patrones de coloración y las características craneales identifican a nuestros especímenes como $N$. olivacea; sin embargo, la distribución disyunta de esta población con respecto a la poblaciones del norte de los Andes podría sugerir alguna diferenciación que merece ser revisada con especímenes adicionales.

\section{Cetartiodactyla}

Dos especies de delfines son reportadas para el Perú, Lagenodelphis hosei por Hammond et al. (2008) y Mesoplodon ginkgodens por Taylor et al. (2008). Sin embargo, estas especies carecen de registros confiables (i.e., especímenes, avistamientos, varamientos o capturas) (J. Reyes y Francis van Oordt, com. pers.) por lo que no son consideradas aquí.

\section{Mazama nemorivaga (F. Cuvier, 1817)}

Se sigue a Duarte et al. (2008) y Rossi y Duarte (2008) quienes asignan esta especie para las poblaciones de la selva amazónica, diferenciándola molecular y citogenéticamente de M. gouazoubira. Duarte et al. (2008) apoyan también el hallazgo inesperado de que Mazama no es un taxon monofilético (Gilbert et al., 2006).

\section{Mazama sp.}

Trolle y Emmons (2004) registran con trampas cámara un pequeño venado del género Mazama en el río Los Amigos, Madre de Dios. Debido a que esta no coincide con alguna especie conocida para la región, los autores sugieren que representaría una nueva especie de venado enano.

\section{Physeter catodon Linnaeus, 1758}

Seguimos a Mead y Brownell, Jr. (2005) en el nombre específico. Sin embargo, aún existe confusión en el uso de catodon o macrocephalus, ambos nombres fueron usados por Linneaus en la décima edición (Linnaeus 1758).

\section{Endemismos}

Cinco géneros (Amphinectomys, Eremoryzomys, Punomys, Cuscomys y Tomopeas) son endémicos para Perú. El murciélago Tomopeas es además endémico del flanco occidental de los Andes; el roedor Cuscomys de las Yungas del sur, Amphinectomys de Selva Baja, Eremoryzomys del valle del Marañón y Punomys de la Puna del sur. A nivel de especies, 65 (12,8\%) son endémicas de Perú, que incluyen a 1 cingulado, 8 didelfimorfios, 7 murciélagos, 3 primates, 45 roedores y 1 soricomorfo (Tabla 2); siendo los roedores el grupo con mayor porcentaje de endémicos (69\%). Asímismo, las Yungas son la ecorregión con mayor cantidad de especies endémicas (39), lo que representa el 60\% de la fauna mamífera endémica. La Selva Baja, aunque muy rica en diversidad, posee sólo 14 especies endémicas, representando un $21,5 \%$ del total.

\section{Conservación}

Según la Lista Roja de la IUCN (2008), 54 especies del Perú $(10,6 \%)$ se encuentran en una categoría de amenaza (Críticamente en peligro, En peligro o Vulnerable); mientras que para la legislación nacional (Decreto Supremo No 034-2004AG), éstas llegan a 59 especies (11,6\%)(Anexo 1). Aunque los porcentajes son semejantes, ambas listas coinciden en sólo 37 especies. Por otro lado, de las 54 especies consideradas amenazas por la IUCN (2008), solo 21 son endémicas para el país. Número seguramente mayor si incluimos a las especies endémicas y amenazadas como las ardillas Sciurus pyrrhinus, S. sanborni; los roedores Neusticomys peruviensis, Rhipidomys ochrogaster, Thomasomys gracilis, T. praetor, T. rosalinda, T. taczanowskii; y el soricomorfo Cryptotis peruviensis. Se observa entonces que la lista 
Tabla 5. Comparación entre las listas de especies de la IUCN 2006 vs IUCN 2008.

\begin{tabular}{lccccccc}
\hline \multirow{2}{*}{ IUCN 2006 } & \multicolumn{7}{c}{ IUCN 2008 } \\
\cline { 2 - 7 } & & CR & EN & VU & NT & LC & DD \\
\hline CR & 5 & 2 & & & & 1 & 2 \\
EN & 9 & & $\mathbf{4}$ & 2 & & 2 & \\
VU & 31 & & 4 & $\mathbf{8}$ & 4 & 9 & 4 \\
NT & 9 & & 1 & 3 & $\mathbf{4}$ & 1 & \\
LC & 328 & 1 & 2 & 10 & 8 & $\mathbf{2 5 8}$ & 27 \\
DD & 29 & & & 2 & 2 & 7 & $\mathbf{1 6}$
\end{tabular}

Categorías de especies Amenazadas (en negrita): $\mathrm{CR}=$ Estado crítico, $\mathrm{EN}=\mathrm{En}$ peligro, VU=Vulnerable. Otras: NT= Casi amenazada, LC= Poca preocupación, $\mathrm{DD}=$ Datos deficientes

de la IUCN (2008) no refleja las prioridades de la conservación de la diversidad del país.

El número de especies amenazadas por la IUCN (2008) con respecto a la versión previa del 2006 ha aumentado, de 45 a 54 especies. Sin embargo, de las 45 especies amenazadas en el 2006 sólo 20 han permanecido en la categoría en la lista del 2008 (Tabla 5). Diecinueve especies amenazadas adicionales han provenido de la recategorización de especies "no amenazadas" de la versión del 2006. Aunque estos resultados parecen indicar un mejor conocimiento de las especies, algunos resultados son de especial preocupación a nivel regional. Por ejemplo, el murciélago longirostro peruano Platalina genovensium, ha sido recategorizado de Vulnerable a Casi amenazado, a pesar de que la información local indica lo contrario (Sahley y Baraybar 1996, Velazco, S., com. pers). El coto negro Alouatta palliata es considerada como de Poca Preocupación; no obstante su presencia en Perú, restringida a un área muy reducida del departamento de Tumbes (Aquino y Encarnación 1994), sugiere que debería estar en alguna categoría de amenaza como otras especies que solo habitan en esta región.

Se ha discutido ampliamente si los criterios de la IUCN son adecuados para establecer prioridades de conservación. Possingham et al. (2002) mencionan por ejemplo que las listas de especies amenazadas (e.g., IUCN 2008) tienen un enfoque global y centrada en las especies, pero no están diseñadas con criterios para priorizar recursos o unidades de conservación. Ceballos et al. (2005) encuentran que las regulaciones internacionales (IUCN, CITES) son inadeacuadas para la protección de la diversidad de mamíferos de México. Es urgente por ello una lista actualizada de especies amenazadas para Perú que además de los criterios de la IUCN, incorpore criterios de amenaza particulares para el país. Incorporar por ejemplo el criterio de endemismo, un tamańo de área de ocurrencia diferente por grupo taxonómico, un valor filogenético dando prioridad a linajes ancestrales (e.g. Lestoros), especies con hábitats sensibles (e.g., Platalina), entre otros.

\section{Discusión}

La diversidad de mamíferos de Perú, con 508 especies registradas en un área bastante menor que Brasil, es notable. Esto es debido en gran parte a los múltiples hábitat, biomas y barreras creados por la Cordillera de los Andes, en un escenario donde la fauna sudamericana nativa (e.g., marsupiales, xenarthros, roedores caviomorfos) y laurásica (e.g., roedores cricétidos, cetartiodáctilos, perisodáctilos, carnívoros), encontraron amplias oportunidades de especiar y radiar.
Perú es un país cuya diversidad está aún pobremente estudiada, a diferencia de Estados Unidos, México o Chile en las Américas. Por ello, revisiones taxonómicas modernas, empleando descripciones morfológicas, cariotípicas y moleculares, son aún una necesidad de primer orden. No sorprende entonces decir que la diversidad real de mamíferos es aún mayor a la aquí reportada. Un estimado de al menos 600 especies no es irrazonable ya que se tiene evidencia basada en especímenes que cerca de 25 especies adicionales están en proceso de ser descritas o en revisión sistemática.

Esta gran diversidad no puede menos que obligar a un mayor compromiso por su conservación. Sin embargo, es lamentable encontrar que el número de especies amenazadas ha incrementado, y más crítico aún encontrar que muchas de ellas son especies endémicas. Estas especies por estar presentes sólo en el país deberían tener una alta prioridad en las políticas de conservación, sean útiles para el desarrollo humano o no. Una meta conservacionista posible y medible debería ser no tener ninguna especie endémica en situación de amenaza.

Finalmente, esta nueva lista pretende ser un punto de referencia para posteriores estudios de diversidad, ecológicos o biogeográficos, a nivel de país o regionales. Como mencionan Pacheco (2002) y Solari (2005) aún son escasos los catálogos regionales (ver Aquino et al. 2001, Williams 2008, Zeballos Patrón et al. 2002), claves de determinación de especies o mapas actualizados de distribución para la mastofauna peruana (ver Pacheco et al. 2007b). No obstante, la creación de la Sociedad Peruana de Mastozoología y las numerosas investigaciones presentadas en el primer Simposio “Avances de la Mastozoología en el Perú” en 2007 y el primer Congreso Peruano de Mastozoología en 2008 (Mena et al. 2008), son promisorios de una nueva y activa era en la mastozoología peruana.

\section{Agradecimientos}

Nuestro agradecimiento a todos nuestros colegas que apoyaron revisando la lista de especies, especialmente a Bruce Patterson (FMNH) y Sergio Solari (UdeA). Igualmente, nuestro agradecimiento a Paul Velazco (FMNH), Julio Reyes (ACOREMA), Francis van Oordt (IMARPE), Jim Patton (MVZ), Robert Voss (AMNH), Alfred Gardner (USNM), Renato Gregorin (UFLA) y Colin Groves (ANU) quienes aportaron con valiosa información o sugerencias. Especial gratitud merecen los miembros y colaboradores del Departamento de Mastozoología del MUSM, en particular Liz Huamaní, Cecilia Barriga, Gisella Márquez, Alicia Vásquez, Carlos Jiménez y Heidi Quintana quienes colaboraron con información, manejo de datos y especímenes, edición, mapas e incontables pero necesarias minucias que permitieron completar este trabajo. Igualmente nuestro agradecimiento a Caroline Pollock (IUCN Species Programme) por el envío de las listas oficiales de especies amenazadas del 2006 y 2008. Catherine Sahley merece un especial reconocimiento por revisar el manuscrito, mejorar el abstract y por el continuo aliciente para llevar este trabajo a término. Dos revisores anónimos contribuyeron sustancialmente con este manuscrito y son particularmente agradecidos. Finalmente, un especial reconocimiento a la Biblioteca del American Museum of Natural History, por permitir al autor senior el acceso a su biblioteca digital, en su condición de Investigador Asociado, sin el cual esta revisión hubiera sido imposible. 


\section{Literatura citada}

ACOREMA. 2009. (en línea). Especies de cetáceos en el Perú. $<$ http://www.acorema.org.pe/des_ec.htm $>$. Acceso 07/05/2009.

Alberico M. \& V. Rojas-Díaz. 2002. Mamíferos de Colombia. In: G. Ceballos y J.A. Simonetti, eds. Diversidad y conservación de los mamíferos neotropicales, Conabio-UNAM, México, D.F. Pp. 185-226.

Alberico M., V. Rojas-Díaz \& J.G. Moreno. 1999. Aporte sobre la taxonomía y distribución de los puercoespines (Rodentia: Erethizontidae) en Colombia. Revista de la Academia Colombiana de Ciencias Exactas Físicas y Naturales 23 (Suplemento Especial): 595-612.

Alberico M., A. Cadena, J. Hernández-Camacho \& Y. Muñoz-Saba. 2000. Mamíferos (Synapsida: Theria) de Colombia. Biota Colombiana 1: 43-75.

Alho C.J.R., M.L. Reis \& P. Seixas. 2002. Mamíferos de Brasil. In: G. Ceballos y J.A. Simonetti, eds. Diversidad y conservación de los mamíferos neotropicales. Conabio-UNAM, México, D.F. Pp. 115-150.

Andersen K. 1906. On the bats of the genera Micronycteris and Glyphonycteris. Annals and Magazine of Natural History, series 7, 18: 50-65.

Aquino R. \& F. Encarnación. 1994. Los primates del Perú. Primate Report 40: 43-129.

Aquino R., R.E. Bodmer \& J.G. Gil. 2001. Mamíferos de la cuenca del río Samiria: Ecología poblacional y sustentabilidad de la caza. Impresión Rosegraf S.R.L., Lima.

Aquino R., W. Terrones, F. Cornejo \& E.W. Heymann. 2008. Geographic distribution and possible taxonomic distinction of Callicebus torquatus populations (Pitheciidae: Primates) in Peruvian Amazonia. American Journal of Primatology 70: $1181-1186$.

Baker R.J., M.M. Mcdonough, V.J. Swier, et al. 2009. New species of bonneted bat, genus Eumops (Chiroptera: Molossidae) from the lowlands of western Ecuador and Peru. Acta Chiropterologica 11(1): 1-13.

Baird A.B., D.M. Hillis, J.C. Patton \& J.W. Bickham. 2008. Evolutionary history of the genus Rhogeessa (Chiroptera: Vespertilionidae) as revealed by mitochondrial DNA sequences. Journal of Mammalogy 89(3): 744-754.

Baird A.B., D.M. Hillis, J.C. Patton \& J.W. Bickham. 2009. Speciation by monobrachial centric fusions: A test of the model using nuclear DNA sequences from the bat genus Rhogeessa. Molecular Phylogenetics and Evolution 50: 256-267.

Barquez R.M., M.M. Díaz \& R.A. Ojeda (editores). 2006. Mamíferos de Argentina, sistemática y distribución. Sociedad Argentina para el Estudio de los Mamíferos. Tucumán. 359pp.

Best T.L., J.L.Hunt, L.A. McWilliams \& K.G. Smith. 2001. Eumops maurus. Mammalian Species 667: 1-3.

Boisserie J.R., F. Lihoreau \& M. Brunet. 2005. The position of Hippopotamidae within Cetartiodactyla. Proceedings of the National Academy of Sciences 102 (5): 1537-1541.

Brack-Egg E. 1986. Las Ecorregiones del Perú. Boletín de Lima 44: 57-70.

Brown B.E. 2004. Atlas of New World marsupials. Fieldiana Zoology (New Series) 102: 1-308.

Ceballos G., J. Arroyo-Cabrales \& R.A. Medellín. 2002. Mamíferos de México. In: G. Ceballos y J.A. Simonetti, eds. Diversidad y conservación de los mamíferos neotropicales. Conabio-UNAM, México, D.F. Pp. 377- 413.

Ceballos G., J. Arroyo-Cabrales, R.A. Medellín \& Y. DomínguezCastellanos. 2005. Lista actualizada de los mamíferos de México. Revista Mexicana de Mastozoología 9: 21-71.
Ceballos G., P. Ortega Baes, S. Sühring, et al. 2002. Mamíferos de Venezuela. In: Ceballos G. y J. A. Simonetti, eds. Diversidad y conservación de los mamíferos neotropicales. Conabio-UNAM, México, D.F. Pp. 567- 582.

Cerqueira R. \& C.J. Tribe. 2008 (2007). Genus Didelphis Linnaeus, 1758. In: A.L. Gardner, ed. Mammals of South America. Volume 1: Marsupials, xenarthrans, shrews, and bats. The University of Chicago Press, Chicago. Pp. 17-25.

CITES 2009. (en línea). Apéndices I, II y III. < www.cites.org/esp/ app/appendices.shtml $>$. Acceso 10/08/2009.

Cossíos D. 2004. La liebre europea, Lepus europaeus (Mammalia, Leporidae), especie invasora en el sur del Perú. Revista Peruana de Biología 11(2): 209-212.

D’Elía G., U.F.J. Pardiñas, P. Jayat \& J. Salazar-Bravo. 2008. Systematics of Necromys (Rodentia, Cricetidae, Sigmodontinae): species limits and groups, with comments on historical biogeography. Journal of Mammalogy 89 (3): 778-790.

Delgado C. \& D. Tirira. 2008. (en línea). Echinoprocta rufescens. In: IUCN 2009. IUCN Red List of Threatened Species. Version 2009.1. <www.iucnredlist.org>. Acceso 01/06/2009.

Davis W.B. \& A.L. Gardner. 2008 (2007). Genus Eptesicus Rafinesque, 1820. In: A.L. Gardner, ed. Mammals of South America, Volume 1. Marsupials, xenarthrans, shrews, and bats. The University of Chicago Press, Chicago. Pp. 440-450.

Del Río M.L., D. Pariona, J.H. Córdova \& G. Salomón. 2001. Las especies exóticas invasoras en el Perú, Primer Informe Nacional. Concejo Nacional del Ambiente. Lima.

de Oliveira L.R., J.I. Hoffman, E. Hingst-Zaher, et al. 2008. Morphological and genetic evidence for two evolutionarily significant units (ESUs) in the South American fur seal, Arctocephalus australis. Conservation Genetics 9 (6): 1451-1466.

Díaz M.M. \& M.R. Willig. 2004. Nuevos registros de Glironia venusta y Didelphis albiventris (Didelphimorphia) para Perú. Mastozoología Neotropical 11: 185-192.

Duarte J.M.B., S. González \& J.E. Maldonado. 2008. The surprising evolutionary history of South American deer. Molecular Phylogenetics and Evolution 49 (1): 17-22.

Eger J. 2008 (2007). Family Molossidae, In: A.L. Gardner, ed. Mammals of South America, Volume 1. Marsupials, xenarthrans, shrews, and bats. The University of Chicago Press, Chicago. Pp. 399-439.

Eisenberg J.F. \& K.H. Redford. 1999. Mammals of the Neotropics. Volume 3. The Central Neotropics: Ecuador, Peru, Bolivia, Brazil. University of Chicago Press, Chicago. 609 pp.

Emmons L.H. 2005. A revision of the genera of arboreal Echimyidae (Rodentia: Echimyidae, Echimyinae), with descriptions of two new genera. In: E. Lacey y P. Myers, eds. Mammalian Diversification: From Chromosomes to Phylogeography (A Celebration of the Career of James L. Patton). University of California Publications in Zoology series 133: 247-310.

Emmons L.H. \& F. Feer. 1997. Neotropical rainforest mammals, a field guide. 2da edn., The University of Chicago Press, Chicago. 307pp.

Emmons L.H. \& F. Feer. 1999. Mamíferos de los bosques húmedos de América tropical. Editorial F.A.N. Santa Cruz de la Sierra. 298 pp.

Emmons L.H., C. Ascorra \& M. Romo. 1994. Mammals of the río Heath and Peruvian pampas. In: R. Foster, J. Carr y A. Forsyth, eds. The Tambopata-Candamo Reserved Zone of southeastern Perú: A biological assessment. RAP Working Papers 6. Conservation International, Washington, D.C. Pp. 146-149. 
Emmons L.H., L. Luna W. \& M. Romo R. 2001. Mammals of the Northern Vilcabamba mountain range, Peru. In: L.E. Alonso, A. Alonso, T.S. Schulenberg \& F. Dallmeier, eds. Biological and social assessments of the Cordillera de Vilcabamba, Peru. RAP Working Papers 12 \& SI/MAB Series 6, Conservation International, Washington, D.C. Pp. 105-109, 255-257.

Emmons L.H., M. Romo, L. Luna, et al. 2002. Anexo 4. Comparación de ocurrencia de especies de mamíferos del SNPH (RAP 1992 y 1996) con otras localidades de Madre de Dios. In: J.R. Montambault, ed. Informes de las evaluaciones biológicas Pampas del Heath, Perú; Alto Madidi, Bolivia; y Pando, Bolivia. Conservation International Bulletin of Biological Assessment 24, Washington, D.C. Pp. 106-110.

Engstrom M.D. \& B.K. Lim. 2002. Mamíferos de Guyana. In: G. Ceballos y J.A. Simonetti, eds. Diversidad y conservación de los mamíferos neotropicales. Conabio-UNAM, México, D.F. Pp. 329-375.

Escomel E. 1929. Fauna de Arequipa. Obras científicas, Lima.

Flores D.A., R.M. Barquez \& M.M. Díaz. 2008. A new species of Philander Brisson, 1762 (Didelphimorphia, Didelphidae). Mammalian Biology 73: 14-24.

Gardner A.L. 2005. Order Didelphimorphia. In: D.E. Wilson y D.A.M. Reeder, eds. Mammal Species of the World: A Taxonomic and Geographic Reference, 3rd edn. Johns Hopkins University Press, Baltimore. Pp. 3-18.

Gardner A.L. (editor). 2008 (2007). Mammals of South America, Volume 1. Marsupials, xenarthrans, shrews, and bats. The University of Chicago Press, Chicago. 669pp.

Gardner A.L. \& G.K. Creighton. 2008 (2007). Genus Micoureus Lesson, 1842. In: A.L. Gardner, ed. Mammals of South America, Volume 1. Marsupials, xenarthrans, shrews, and bats. The University of Chicago Press, Chicago. Pp. 74-82.

Gardner A.L. \& J.L. Patton. 1976. Karyotypic variation in oryzomyine rodents (Cricetinae) with comments on chromosomal evolution in the Neotropical cricetine complex. Occasional Papers of the Museum of Zoology, Louisiana State University 49: 1-48.

Gatesy J., M. Milinkovitch, V. Waddell \& M. Stanhope. 1999. Stability of cladistic relationships between Cetacea and higher level artiodactyl taxa. Systematic Biology 48:6-20.

Geisler J.H. \& M.D. Uhen. 2003. Morphological support for a close relationship between hippos and whales. Journal of Vertebrate Paleontology 23: 991-996.

Geisler J.H. \& M.D. Uhen. 2005. Phylogenetic relationships of extinct cetartiodactyls: Results of simultaneous analyses of molecular, morphological, and stratigraphic data. Journal of Mammalian Evolution 12(1-2): 145-160.

Genoways H.H. \& R.J. Baker. 1996. A new species of the genus Rhogeessa, with comments on geographic distribution and speciation in the genus. In: H.H. Genoways y R.J. Baker, eds. Contributions in mammalogy: a memorial volume honoring Dr. J. Knox Jones, Jr. The Museum, Texas Tech University, Lubbock. Pp. 83-87.

Genoways H.H. \& S.L. Williams. 1979. Records of bats (Mammalia: Chiroptera) from Suriname. Annals of the Carnegie Museum 48: 323 - 335.

Gilbert C., A. Ropiquet \& A. Hassanin. 2006. Mitochondrial and nuclear phylogenies of Cervidae (Mammalia, Ruminantia): systematics, morphology, and biogeography. Molecular Phylogenetics and Evolution 40: 101-117.

Gentry A., J. Clutton-Brock \& C.P. Groves. 2004. The naming of wild animal species and their domestic derivates. Journal of Archaeological Science 31: 645- 651.

González E. 2001. Guía de campo de los mamíferos de Uruguay. Vida Silvestre Sociedad Uruguaya para la Conservación de la Naturaleza. Montevideo.
González del Solar R. \& J.R. Rau. 2004. Chilla, Pseudalopex griseus (Gray 1837). In: C. Sillero-Zubiri, M. Hoffman y D. W. Macdonald, eds. Canids: foxes, wolves, jackals, and dogs. Status survey and conservation action plan. International Union for Conservation of Nature and Natural Resources/ Species Survival Commission Canid Specialist Group, Gland, Switzerland. Pp. 56-63.

Gregorin R. 2006. Taxonomy and geographic variation of species of the genus Alouatta Lacépède (Primates, Atelidae) in Brazil. Revista Brasileira de Zoologia 23 (1): 64-144.

Gregorin R. \& V. Taddei. 2002. Chave artificial para a identificação de molossídeos brasileiros (Mammalia, Chiroptera). Mastozoología Neotropical 9(1): 13 - 32.

Griffith T. \& A.L. Gardner. 2008 (2007). Subfamily Glossophaginae. In: A.L. Gardner, ed. Mammals of South America, Volume 1. Marsupials, xenarthrans, shrews, and bats. The University of Chicago Press, Chicago. Pp. 224-244.

Grimwood I.R. 1969. Notes on the distribution and status of some Peruvian mammals. American Commitee for International Wild Life Protection and New York Zoological Society, Special Publication 21: 1-86.

Groves C.P. 2001. Primate taxonomy. Smithsonian Institution Press, Washington, D.C. viii + 350pp.

Groves C.P. 2005. Order Primates. In: D.E. Wilson y D.M. Reeder, eds. Mammal Species of the World. 3rd edn. Johns Hopkins University Press, Baltimore. Pp. 111-184.

Hammond P.S., G. Bearzi, A. Bjørge, et al. 2008. (en línea). Lagenodelphis hosei. In: IUCN 2009. IUCN Red List of Threatened Species. Version 2009.1. <www.iucnredlist. org > . Acceso 01/06/2009.

Hanson J.D. \& R.D. Bradley. 2008. Molecular diversity within Melanomys caliginosus (Rodentia: Oryzomyini): evidence for multiple species. Occasional Papers Museum of Texas Tech University 275: 1-11.

Hershkovitz P. 1990. Titis, New World monkeys of the genus Callicebus (Cebidae, Platyrrhini): a preliminary taxonomic review. Fieldiana Zoology (New Series) 55: 1-109.

Hoofer S.R., S. Solari, P.A. Larsen, et al. 2008. Phylogenetics of the fruit-eating bats (Phyllostomidae: Artibeina) inferred from mitochondrial DNA sequences. Occasional Papers Museum Texas Tech University 277: 1-15.

Hutterer R. 2005. Order Soricomorpha. In: D.E. Wilson y D.M. Reeder, eds. Mammal species of the world: a taxonomic and geographic reference. 3rd edn. vol. 1. The Johns Hopkins University Press, Baltimore. Pp. 220-311.

IUCN 2008. (en línea). IUCN Red list of threatened species. Version $2008<$ www.iucnredlist.org $>$. Acceso 27/11/2008.

IUCN, Conservation International, Arizona State University, Texas A\&M University, University of Rome, University of Virginia, Zoological Society London. 2008. (en línea). An analysis of mammals on the 2008 IUCN Red List $<$ www. iucnredlist.org/mammals>. Acceso 09/10/2008.

Jarrín P. 2001. Mamíferos en la Niebla. Otonga, Un Bosque Nublado del Ecuador. Museo de Zoología, Centro de Biodiversidad y Ambiente, Pontificia Universidad Católica del Ecuador, $244 \mathrm{pp}$.

Jiménez C., M. Peralta \& V. Pacheco. 2008. Inventario preliminar de la mastofauna presente en el área propuesta de Conservación Biregional Amazonas-San Martín. I Congreso de la Sociedad Peruana de Mastozoología Cusco-Perú. Libro Resúmenes. $127 \mathrm{pp}$.

Kajin M., R. Cerqueira, M.V. Vieira \& R. Gentile. 2008. Nine-year demography of the black-eared opossum Didelphis aurita (Didelphimorphia: Didelphidae) using life tables. Revista Brasileira de Zoologia 25 (2): 206-213.

Lanzone C. \& R.A. Ojeda. 2005. Citotaxonomía y distribución del género Eligmodontia (Rodentia, Cricetidae, Sigmodontinae), Mastozoología Neotropical 12(1): 73-77. 
Lanzone C., R.A. Ojeda \& M.H. Gallardo. 2007. Integrative taxonomy, systematics and distribution of the genus Eligmodontia (Rodentia, Cricetidae, Sigmodontinae) in the temperate Monte Desert of Argentina. Mammalian Biology 72 (5): 299-312.

LaVal R.K. 1973. Systematics of the genus Rhogeessa (Chiroptera: Vespertilionidae). Occasional Papers of the Museum of Natural History, University of Kansas, 19: 1-47.

Linares O.J. 1987. Murciélagos de Venezuela, Cuadernos Lagoven. $122 \mathrm{pp}$.

Linnaeus C. 1758. Systema naturae per regna tria naturae, secundum classes, ordines, genera, species, cum characteribus, differentiis, synonymis, locis. 10th ed. Vol. 1. Stockholm: Laurentii Salvii.

Lleellish M., R. Cadenillas \& G. Chipana. 2007. Presencia de la liebre europea Lepus europaeus en el departamento de Tacna. 9 pp. Serie de Publicaciones de Flora y Fauna Silvestre. Instituto Nacional de Recursos Naturales, Lima, Perú.

Lönnberg E. 1939. Remarks on some members of the genus Cebus. Arkiv för Zoologi, Stockholm, 31A: 1-24.

Lopatin A.V. 2006. Early Paeogene insectivore mammals of Asia and establishment of the major groups of Insectivora. Paleontological Journal 40 (3): 205-405.

Lucherini M., M. Pessino \& A.A. Farias. 2004. Pampas fox, Pseudalopex gymnocercus (G. Fischer, 1814). In: C. Sillero-Zubiri, M. Hoffman y D. W. Macdonald, eds. Canids: foxes, wolves, jackals, and dogs. Status survey and conservation action plan. International Union for Conservation of Nature and Natural Resources/Species Survival Commission Canid Specialist Group, Gland, Switzerland. Pp. 63-68.

Luna L., L. Emmons, M. Romo \& A. Cornejo Farfán. 2002. Mamíferos encontrados en el Santuario Nacional Pampas del Heath durante la expedición del RAP de 1996. In: J. R. Montambault, ed. Informes de las evaluaciones biológicas Pampas del Heath, Perú; Alto Madidi, Bolivia; y Pando, Bolivia. Conservation International, Bulletin of Biological Assessment 24, Washington, D.C. Pp. 66-70.

Macdonald D. 1984. The Encyclopedia of mammals. Facts on File Publications Inc. New York. 895pp.

Mantilla-Meluk H. \& R.J. Baker. 2006. Systematics of small Anoura (Chiroptera: Phyllostomidae) from Colombia, with description of a new species. Occasional Papers, Museum of Texas Tech 261: 1-18.

Mantilla-Meluk H. \& R.J. Baker. 2008. Mammalia, Chiroptera, Phyllostomidae, Anoura fistulata: Distribution extension. Check List 4(4): 427-430.

Mares M.A., J.K. Braun, B.S. Coyner \& R.A. Van Den Bussche. 2008. Phylogenetic and biogeographic relationships of gerbil mice Eligmodontia (Rodentia, Cricetidae) in South America, with a description of a new species. Zootaxa 1753: $1-33$

Marques-Aguilar S.A. 2008 (2007). Genus Artibeus Leach, 1821. In: A.L. Gardner, ed. Mammals of South America: Volume 1 Marsupials, xenarthrans, shrews, and bats. University of Chicago Press. Pp. 301-321.

Martínez J. 2004. Carnívoros del Ecuador. Anatomía, morfología y clave gráfica de identificación. Universidad del Azuay y Museo de Esqueletología, Cuenca, Ecuador, 160 pp.

Matthews L.J. \& A.L. Rosenberger. 2008. Taxon combinations, parsimony analysis (PAUP*), and the taxonomy of the yellow-tailed woolly monkey, Lagothrix flavicauda. American Journal of Physical Anthropology 137: 245-255.

Mead J. \& R. Brownell Jr. 2005. Order Cetacea. In: D.E. Wilson y D.M. Reeder, eds. Mammal Species of the World. A Taxonomic and Geographic Reference. 3rd edn. John Hopkins University Press, Baltimore. Pp. 723-743.
Mena J.L., V. Pacheco \& C. T. Sahley. 2008. Notas sobre el I Congreso Peruano de Mastozoología, Cusco, Perú. Mastozoología Neotropical 15 (2): 366-367.

Mena J.L., A. Dosantos, J.G. Gil, et al. 2007. Primer registro de Saguinus fuscicollis melanoleucus (Miranda Ribeiro, 1912) en la Amazonía peruana. Revista Peruana de Biología 14(1): 39-42.

Mella J.E., J.A. Simonetti, A.E. Spotorno \& L.C. Contreras. 2002. Mamíferos de Chile, In: G. Ceballos y J.A. Simonetti, eds. Diversidad y conservación de los mamíferos neotropicales. Conabio-UNAM, México, D.F. Pp. 151-183.

Miller G.S., Jr. 1902. Twenty new American bats. Proceedings of the Academy of Natural Sciences of Philadelphia 54: 389-412.

Ministerio de Agricultura. 2004. Decreto Supremo No. 034-2004AG. El Peruano. Pp: 276853-276855.

Muchhala N., P. Mena \& L. Albuja. 2005. A new species of Anoura (Chiroptera: Phyllostomidae) from the Ecuadorian Andes. Journal of Mammalogy 86(3): 457-461.

Muñoz-Pedreros A. 2000. Orden Rodentia. In: A. Muñoz-Pedreros y J. Yáñez-Valenzuela, eds. Mamíferos de Chile. CEA Ediciones, Valdivia. Pp. 73-126.

Muñoz-Pedreros A. \& J Yáñez-Valenzuela, eds. 2000. Mamíferos de Chile. Centro de Estudios Agrarios y Ambientales (CEA) Ediciones, Valdivia. viii $+464 \mathrm{pp}$.

Musser G.G. \& M.D. Carleton. 2005. Superfamily Muroidea, In: D.E. Wilson y D.A.M. Reeder, eds. Mammal species of the World: A taxonomic and geographic reference. 3rd edn. Johns Hopkins University Press, Baltimore. Pp. 894-1531.

Musser G.G., M.D. Carleton, E.M. Brothers \& A.L. Gardner. 1998. Systematic studies of oryzomyine rodents (Muridae: Sigmodontinae): Diagnoses and distributions of species formerly assigned to Oryzomys "capito". Bulletin of the American Museum of Natural History 236: 1-376.

Myers P., A. Taber \& I. Gamarra de Fox. 2002. La mastozoología en Paraguay. In: G. Ceballos y J.A. Simonetti, eds. Diversidad y conservación de los mamíferos neotropicales. ConabioUNAM, México, D.F. Pp. 453-502.

Nowak R.M. 1999. Walker's mammals of the World, 6th ed., Volume I. The Johns Hopkins University Press, Baltimore, $836 \mathrm{pp}$.

Pacheco V. 2002. Mamíferos del Perú. In: G. Ceballos y J. Simonetti, eds. Diversidad y conservación de los mamíferos neotropicales. Conabio-UNAM. México, D.F. Pp. 503-550.

Pacheco V., H. de Macedo, E. Vivar, et al. 1995. Lista anotada de los mamíferos peruanos. Occasional Papers in Conservation Biology 2: 1-35.

Pacheco V., R. Cadenillas, S. Velazco, et al. 2007a. Noteworthy bat records from the Pacific Tropical rainforest region and adjacent dry forest in northwestern Peru. Acta Chiropterologica 9(2): 409-422.

Pacheco V., H.L. Quintana, P.A. Hernandez, et al. 2007b. Mamíferos. In: B.E. Young, ed. Distribución de las especies endémicas en la vertiente oriental de los Andes en Perú y Bolivia. NatureServe, Arlington, Virginia. Pp. 40-45.

Pacheco V., R. Cadenillas, L. Huamaní, et al. 2008a. Diversidad de Mamíferos del Dosel Arbóreo en la Reserva Nacional de Tumbes. XVII Reunión Científica del Instituto de Investigación de Ciencias Biológicas "Antonio Raimondi" ICBAR. Libro Resúmenes. 47pp.

Pacheco V., E. Salas, L. Cairampoma, et al. 2008b (2007). Contribución al conocimiento de la diversidad y conservación de los mamíferos en la cuenca del río Apurímac, Perú. Revista Peruana de Biología 14(2): 169-180.

Paredes U. 2003. Relaciones filogenéticas dentro del género Lagothrix Mono Choro (Primates, Atelidae). Tesis para optar el título de Biólogo. UNMSM. 
Patterson B.D. \& P. Velazco. 2006. A distinctive new cloud-forest rodent (Hystricognathi: Echimyidae) from the Manu Biosphere Reserve, Peru. Mastozoología Neotropical 13: 175-191.

Patton J.L., M.N.F. da Silva \& J.R. Malcolm. 2000. Mammals of the Rio Juruá and the evolutionary and ecological diversification of Amazonia. Bulletin of the American Museum of Natural History 244: 1-306.

Pearson O.P. \& J.L. Patton. 1976. Relationships among South American phyllotine rodents based on chromosome analysis. Journal of Mammalogy 57: 339-350.

Pearson O.P. \& C. Pearson. 1978. The diversity and abundance of vertebrates along an altitudinal gradient in Peru. Memorias del Museo de Historia Natural "Javier Prado" 18: 1-97.

Percequillo A.R., E. Hingst-Zaher, \& C.R. Bonvicino. 2008. Systematic review of genus Cerradomys Weksler, Percequillo and Voss, 2006 (Rodentia: Cricetidae: Sigmodontinae: Oryzomyini), with description of two new species from eastern Brazil. American Museum Novitates 3622: 1-46.

Peres C.A., J.L. Patton \& M.N. da Silva. 1996. Riverine barriers and gene flow in Amazonian Saddle-Back Tamarins. Folia Primatologica 67: 113-124.

Possingham H.P., S.J. Andelman, M.A. Burgman, et al. 2002. Limits to the use of threatened species lists. Trends in Ecology \& Evolution 17(11): 503-507.

Pulido V. \& C. Yockteng. 1986. Conservación de la fauna silvestre en el Bosque Nacional de Tumbes, con especial referencia al "coto mono". In: P. Aguilar, ed. Simposio Conservación y Manejo de la Fauna Silvestre Neotropical. IX CLAZ Perú. Lima. Pp. 33-43.

Quintana V., J. Yáñez \& M. Valdebenito. 2000. Orden Carnivora. In: A. Muñoz-Pedreros y J. Yáñez-Valenzuela, eds. Mamíferos de Chile. CEA Ediciones, Valdivia. Pp. 155-188.

Redondo R.A., L.P. Brina, R.F. Silva, et al. 2008. Molecular systematics of the genus Artibeus (Chiroptera: Phyllostomidae). Molecular Phylogenetics and Evolution 49: 44-58.

Reeder D.M., K. M. Helgen \& D. E. Wilson. 2007. Global trends and biases in new mammal species discoveries. Occasional Papers, Museum of Texas Tech University 269: 1-35

Reid F. \& K. Helgen. 2008. (en línea). Nasuella olivacea. In: IUCN 2009. IUCN Red List of Threatened Species. Version 2009.1. <www.iucnredlist.org>. Acceso 01/06/2009.

Reis N.R., A.L. Peracchi, W.A. Pedro \& I.P. Lima. 2006. Mamíferos do Brasil. Universidade Estadual de Londrina, Londrina. $437 \mathrm{pp}$.

Rodriguez J.J. 1998. Mamíferos de la zona reservada de Tumbes. In: W. Wust, ed. La Zona Reservada de Tumbes. Biodiversidad y Diagnóstico Socioeconómico. PROFONANPE, Lima. Pp. 67-77.

Romo M., L. Luna \& A. Cornejo-Farfán. 2002. Mamíferos encontrados en el Santuario Nacional Pampas del Heath. In: J.R. Montambault, ed. Informes de las evaluaciones biológicas Pampas del Heath, Perú, Alto Madidi, Bolivia y Pando, Bolivia. RAP Bulletin of Biological Assessment 24. Conservation International, Washington, D.C. Pp. 66-69.

Rossi, R.V. \& Duarte, J.M.B 2008. (en línea). Mazama nemorivaga. In: IUCN 2008. 2008 IUCN Red List of Threatened Species. <www.iucnredlist.org>. Acceso 08/11/2008.

Rylands A.B., M.C.M. Kierulff \& R.A. Mittermeier. 2005. Notes on the taxonomy and distribution of the tufted capuchin monkeys (Cebus, Cebidae) of South America. Lundiana 6(suplemento): 97-110.

Sahley C. \& L. Baraybar. 1996. Natural history of the Long-Snouted Bat, Platalina genovensium (Phyllostomidae: Glossophaginae) in Southwestern Peru. Vida Silvestre Neotropical 5(2): 101-109.
Salazar Bravo J., T.L. Yates \& L. Marcelo Zalles. 2002. Mamíferos de Bolivia. In: G. Ceballos y J.A. Simonetti, eds. Diversidad y conservación de los mamíferos neotropicales. ConabioUNAM, México, D.F. Pp. 65-113.

Salazar Bravo J., T. Tarifa, L.F. Aguirre, et al. 2003. Revised Checklist of Bolivian Mammals Occasional Papers Museum of Texas Tech University 220: 1-27.

Simmons N.B. 1996. A new species of Micronycteris (Chiroptera: Phyllostomidae) from Northeastern Brazil, with comments on phylogenetic relationships. American Museum Novitates 3158: 1-34

Simmons N.B. 2005. Order Chiroptera. In: D.E. Wilson y D.M. Reeder, eds. Mammal species of the world: a taxonomic and geographic reference. 3rd edn. vol. 1. The Johns Hopkins University Press, Baltimore. Pp. 312-529.

Simmons N.B. \& R.S. Voss. 1998. The mammals of Paracou, French Guiana: a Neotropical lowland rainforest fauna. Part 1. Bats. Bulletin of the American Museum of Natural History 237: 1-219.

Smith M.F. \& J.L. Patton. 2007. Molecular phylogenetics and diversification of South American grass mice, genus Akodon. In: D.A. Kelt, E.P. Lessa, J. Salazar-Bravo y J. L. Patton, eds. The Quintessential Naturalist: Honoring the Life and Legacy of Oliver P. Pearson. University of California Publications in Zoology 134:1-981. Pp. 827-858.

Sodré M.M., A.R da Rosa, R. Gregorin \& M.M. Guimarães. 2008. Range extension for Thomas' Mastiff bat Eumops maurus (Chiroptera: Molossidae) in northern, central and southeastern Brazil. Revista Brasileira de Zoologia 25 (2): 379-382.

Solari S. 2005. Perspectivas de la mastozoología en el Perú. Mastozoología Neotropical 12: 3-7.

Solari S. 2007. New species of Monodelphis (Didelphimorphia: Didelphidae) from Peru, with notes on M. adusta (Thomas, 1897). Journal of Mammalogy 88(2): 319-329.

Solari S., E. Vivar, P.M. Velazco \& J.J. Rodriguez. 2001. Small mammals of the southern Vilcabamba region, Peru. In: L.E. Alonso, A. Alonso, T.S. Schulenberg y F. Dallmeier, eds. Biological and social assessments of the Cordillera de Vilcabamba, Peru. RAP Working Papers 12, and SIMAB Series 6, Conservation International, Washington, D.C. Pp. 110-116.

Solari S., V. Pacheco, L. Luna, et al. 2006. Mammals of the Manu Biosphere Reserve. In: B.D. Patterson, D.F. Stotz y S. Solari, Eds. Mammals and birds of the Manu Biosphere Reserve, Peru. Fieldiana Zoology (New Series) 110: 13-22.

Soriano P.J. \& J. Ochoa. 1997. Lista actualizada de los mamíferos de Venezuela. In: E. La Marca, ed. Vertebrados actuales y fósiles de Venezuela. Serie Catálogos Zoológicos de Venezuela, Fundacite Mérida, Mérida. Pp. 203-227.

Spotorno A.E., L.I. Walker, S.V. Flores, et al. 2001. Evolución de los filotinos (Rodentia, Muridae) en los Andes del Sur. Revista Chilena de Historia Natural 74: 151-166.

Stein B.R. \& J.L. Patton. 2008 (2007). Genus Lutreolina O. Thomas, 1910. In: A.L. Gardner, ed. Mammals of South America, Volume 1. Marsupials, xenarthrans, shrews, and bats. The University of Chicago Press, Chicago. Pp. 25-27.

Steppan S.J., O. Ramirez, J. Banbury, et al. 2007. A molecular reappraisal of the systematics of the leaf-eared mice Phyllotis and their relatives. In: D.A. Kelt, E.P. Lessa, J. Salazar-Bravo \& J.L. Patton, eds. The Quintessential Naturalist: Honoring the Life and Legacy of Oliver P. Pearson. University of California Publications in Zoology 134:1-981. Pp. 799-826.

Tarifa T. 2005. Desarrollo y perspectivas de la mastozoología en Bolivia: una historia de pioneros bolivianos y padres extranjeros. Mastozoología Neotropical 12(2): 125-132. 
Taylor B.L., R. Baird, J. Barlow, et al. 2008. (en línea). Mesoplodon ginkgodens. In: IUCN 2009. IUCN Red List of Threatened Species. Version 2009.1. <www.iucnredlist.org>. Acceso 01/06/2009.

Tello C., C. Ascorra \& V. Pacheco. 2008. Diversidad de murciélagos de la cuenca de río Napo, Loreto, Perú. I Congreso de la Sociedad Peruana de Mastozoología Cusco-Perú, Libro Resúmenes. 115pp.

Teta P. \& D.C. de Tommaso. 2009. Un registro marginal para la comadreja overa Didelphis albiventris (Didelphimorphia, Didelphidae) en la provincia de San Juan, Argentina. Nótulas Faunísticas, Segunda Serie 27: 1-3.

Thomas O. 1914. New South-American rodents. Annals and Magazine of Natural History, series 8, 14: 240-244.

Tirira D. 2004. Nombres de los mamíferos del Ecuador. Publicación Especial sobre los mamíferos del Ecuador 5. Ediciones Murciélago Blanco y Museo Ecuatoriano de Ciencias Naturales. Quito. 267pp.

Tirira D. 2007. Mamíferos del Ecuador, Guía de Campo. Publicación Especial 6. Ediciones Murciélago Blanco. Quito.

Trolle M. \& L.H. Emmons. 2004. A record of a dwarf brocket from lowland Madre de Dios, Perú. Deer News 19: 2-5.

Van Roosmalen M.G.M., T. Van Roosmalen \& R.A. Mittermeier. 2002. A taxonomic review of the titi monkeys, genus Callicebus Thomas, 1903, with the description of two new species, Callicebus bernhardi and Callicebus stephennashi, from Brazilian Amazonia. Neotropical Primates 10 Supplement: 1-52.

Velazco P.M. 2005. Morphological phylogeny of the bat genus Platyrrhinus Saussure, 1860 (Chiroptera:Phyllostomidae) with the description of four new species. Fieldiana Zoology (new series) 105: 1-53.

Velazco P.M. \& B.D. Patterson. 2008. Phylogenetics and biogeography of the broad-nosed bats, genus Platyrrhinus (Chiroptera: Phyllostomidae). Molecular Phylogenetics and Evolution 49(3): 749-759.

Vivar E., V. Pacheco \& M. Valqui. 1997. A new species of Cryptotis (Insectivora: Soricidae) from Northern Peru. American Museum Novitates 3202: 1-15.

Vonhof M.J. 2000. Rhogeessa tumida. Mammalian Species 633: 1-3.

Voss R.S. \& S.A. Jansa. 2003. Phylogenetic studies on Didelphid marsupials II. Nonmolecular data and new IRBP sequences: separate and combined analyses of Didelphine relationships with denser taxon sampling. Bulletin of the American Museum of Natural History 276: 1-82.

Voss R.S. \& S.A. Jansa. 2009. Phylogenetic relationships and classification of didelphid marsupials, an extant radiation of New World metatherian mammals. Bulletin of the American Museum of Natural History 322: 1-177.

Voss R.S., D.W. Fleck \& S.A. Jansa. En prensa. On the diagnostic characters, ecogeographic distribution, and phylogenetic relationships of Gracilinanus emiliae (Didelphimorphia: Didelphidae: Thylamyini). Mastozoología Neotropical.

Voss R.S., D.P. Lunde \& S.A. Jansa. 2005. On the contents of Gracilinanus Gardner and Creighton, 1989, with the description of a previously unrecognized clade of small didelphid marsupials. American Museum Novitates 3482: 1-34.

Voss R.S., D.P. Lunde \& N.B. Simmons. 2001. The mammals of Paracou, French Guiana: A Neotropical lowland rainforest fauna part 2. Nonvolant species. Bulletin of the American Museum of Natural History 263: 1-236.
Waddell P.J. \& S. Shelley. 2003. Evaluating placental inter-ordinal phylogenies with novel sequences including RAG1, $\gamma$ -fibrinogen, ND6, and mt-tRNA, plus MCMC-driven nucleotide, amino acid, and codon models. Molecular Phylogenetics and Evolution 28: 197-224.

Waddell P., N. Okada \& M. Hasegawa. 1999. Towards resolving the interordinal relationships of placental mammals. Systematic Biology 48 (1): 1-5.

Wallace R.B., H. Gómez, A. Felton \& A.M. Felton. 2006. On a new species of Titi monkey, genus Callicebus Thomas (Primates, Pitheciidae), from western Bolivia with preliminary notes on distribution and abundance. Primate Conservation 20: 29-39.

Wallace R.B., de La Torre, S. \& L.M. Veiga. 2008. (en línea). Callicebus aureipalatii. In: IUCN 2008. 2008 IUCN Red List of Threatened Species. <www.iucnredlist.org > Acceso 06/04/2009.

Wayne R.K., E. Geffen, D.J. Girman, et al. 1997. Molecular systematics of the Canidae. Systematic Biology 46(4): 622-653.

Weksler M., A.R. Percequillo \& R.S. Voss. 2006. Ten new genera of Oryzomyine rodents (Cricetidae: Sigmodontinae). American Museum Novitates 3537: 1-29.

Williams R. 2008. Mamíferos de Chaparrí. In: H. Plenge y R. Williams, eds. Guía de la vida silvestre de Chaparrí. Lima: Geográfica EIRL. Pp. 78-85, 103.

Williams S.L. \& H.H. Genoways. 2008 (2007). Subfamily Phyllostominae Gray. 1825. In: A.L. Gardner, ed. Mammals of South America, Volume 1. Marsupials, xenarthrans, shrews, and bats. The University of Chicago Press, Chicago. Pp. 255- 300.

Wilson D.E. \& D.M. Reeder, eds. 2005. Mammal Species of the World: A Taxonomic and Geographic Reference. 3rd edn. Johns Hopkins University Press, Baltimore. 2142 pp.

Woodman N. \& J.E. Pefaur. 2008 (2007). Order Soricomorpha Gregory, 1910. Pp. 177-187 in Mammals of South America. Volume I: Marsupials, Xenarthrans, Shrews, and Bats (Gardner, A.L.). University of Chicago Press.

Woodman N. \& R.M. Timm. 2006. Characters and phylogenetic relationships of nectar-feeding bats, with descriptions of new Lonchophylla from western South America (Mammalia: Chiroptera: Phyllostomidae: Lonchophyllini). Proceedings Biological Society of Washington 119 (4): 437-476.

Woods C.A. \& C.W. Kilpatrick. 2005. Infraorder Hystricognathi. In: D.E. Wilson y D.M. Reeder, eds. Mammal species of the world. 3rd edn. Volume 2. The Johns Hopkins University Press, Baltimore. Pp. 1538-1600.

Zeballos H., L. Villegas, R. Gutiérrez, et al. 2000. Vertebrados de las Lomas de Atiquipa y Mejía, sur del Perú. Revista de Ecología Latinoamericana 7 (3): 11-15.

Zeballos Patrón H., V. Pacheco \& L. Baraybar. 2002 (2001). Diversidad y conservación de los mamíferos de Arequipa, Perú. Revista Peruana de Biología 8(2): 94-104.

Zrzavý J. \& V. Řičánková. 2004. Phylogeny of recent Canidae (Mammalia, Carnivora): relative reliability and utility of morphological and molecular datasets. Zoologica Scripta 33(4): 311-333.

Zunino G., O.B. Vaccaro, M. Canevari \& A.L. Gardner. 1995. Taxonomy of the genus Lycalopex (Carnivora: Canidae) in Argentina. Proceedings of the Biological Society of Washington 108(4): 729-745. 
Pacheco et Al.

Anexo 1. Lista de especies de mamíferos registrados para el Perú, con datos de distribución por ecorregiones (sensu Brack-Egg, 1986), de endemismo y categorías de conservación nacional (DS No 034-2004-AG) e internacional (IUCN, 2008; CITES, 2009). Las abreviaturas empleadas son: OCE, Oceánica; BPP, Bosque Pluvial del Pacífico; BSE, Bosque Seco Ecuatorial; DES, Desierto Costero; SE, Serranía Esteparia; PAR, Páramo; PUN, Puna; YUN, Yungas; SB, Selva Baja; SP, Sabana de Palmera; END, Especie endémica; EX, extinta; CR, criticamente en peligro; EN, en peligro; VU, Vulnerable; I = Apéndice I CITES; II = Apéndice II CITES.

\begin{tabular}{|c|c|c|c|c|c|c|c|c|c|c|c|c|c|c|c|c|}
\hline \multicolumn{2}{|c|}{ Nombre científico } & Nombre común & ठำ & 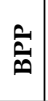 & 跑 & $\begin{array}{c}n \\
\text { Tn } \\
0\end{array}$ & $\frac{\pi}{\omega}$ & $\underset{\Xi}{\Xi}$ & Z & Z & के & $\hat{\omega}$ & $\sum_{i=1}^{0}$ & \begin{tabular}{|l|}
$Z$ \\
Z \\
\end{tabular} & 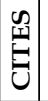 & 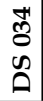 \\
\hline \multicolumn{17}{|c|}{ Didelphimorphia } \\
\hline \multicolumn{17}{|c|}{ Didelphidae } \\
\hline 1 & Caluromys lanatus (Olfers, 1818) & Zarigüeyita lanuda & & & & & & & & 1 & 1 & 1 & & & & \\
\hline 2 & Caluromysiops irrupta Sanborn, 1951 & Zarigüeyita de estola negra & & & & & & & & & 1 & & & & & \\
\hline 3 & Glironia venusta Thomas, 1912 & Zarigüeyita de cola poblada & & & & & & & & & 1 & & & & & \\
\hline 4 & Chironectes minimus (Zimmermann, 1780) & Zarigüeyita acuática, cuica de agua & & & & & & & & 1 & 1 & & & & & \\
\hline 5 & Didelphis marsupialis Linnaeus, 1758 & $\begin{array}{l}\text { Zarigüeya orejinegra, carachupa, } \\
\text { intuto }\end{array}$ & & 1 & 1 & & & & & 1 & 1 & 1 & & & & \\
\hline 6 & Didelphis pernigra J. A. Allen, 1900 & Zarigüeya andina de orejas blancas & & & & 1 & 1 & & & & & & & & & \\
\hline 7 & Gracilinanus aceramarcae (Tate, 1931) & Marmosa grácil & & & & & & & & 1 & & & & & & \\
\hline 8 & Gracilinanus agilis (Burmeister, 1854) & Comadrejita marsupial ágil & & & & & & & & & 1 & & & & & \\
\hline 9 & Gracilinanus emiliae (Thomas, 1909) & Comadrejita marsupial de Emilia & & & & & & & & & 1 & & & & & \\
\hline 10 & Hyladelphys kalinowskii (Hershkovitz, 1992) & $\begin{array}{l}\text { Marmosa grácil de Kalinowski, } \\
\text { comadrejita marsupial peruana }\end{array}$ & & & & & & & & 1 & 1 & & & & & \\
\hline 11 & Lutreolina crassicaudata (Desmarest, 1804) & $\begin{array}{l}\text { Comadreja colorada, zarigüeya de } \\
\text { cola gruesa }\end{array}$ & & & & & & & & & & 1 & & & & \\
\hline 12 & Marmosa andersoni Pine, 1972 & Comadrejita marsupial de Anderson & & & & & & & & & 1 & & 1 & & & \\
\hline 13 & Marmosa lepida (Thomas, 1888) & Comadrejita marsupial radiante & & & & & & & & & 1 & & & & & \\
\hline & Marmosa murina (Linnaeus, 1758) & Comadrejita marsupial ratona & & & & & & & & & 1 & & & & & \\
\hline 15 & Marmosa quichua Thomas, 1899 & Marmosa quechua, marmosa enana & & & & & & & & 1 & 1 & & 1 & & & \\
\hline 16 & Marmosa robinsoni Bangs, 1898 & Comadrejita marsupial de Robinson & & 1 & 1 & & & & & & & & & & & \\
\hline 17 & Marmosa rubra Tate, 1931 & Comadrejita marsupial rojiza & & & & & & & & & 1 & & & & & \\
\hline & Marmosa (Micoureus) demerarae Thomas, 1905 & Comadrejita marsupial lanuda & & & & & & & & 1 & 1 & & & & & \\
\hline 19 & Marmosa (Micoureus) phaea Thomas, 1899 & Raposa chica lanuda & & 1 & & & & & & & & & & $\mathrm{VU}$ & & \\
\hline 20 & Marmosa (Micoureus) regina Thomas, 1898 & Comadrejita marsupial reina & & & & & & & & 1 & 1 & & & & & \\
\hline 21 & Marmosops bishopi (Pine, 1981) & Comadrejita marsupial de Bishop & & & & & & & & & 1 & & & & & \\
\hline 22 & Marmosops impavidus (Tschudi, 1845) & Comadrejita marsupial pálida & & & & & & & & 1 & 1 & & & & & \\
\hline 23 & Marmosops juninensis (Tate, 1931) & Comadrejita marsupial de Junín & & & & & & & & 1 & & & 1 & $\mathrm{Vu}$ & & \\
\hline & Marmosops neblina Gardner, 1990 & Raposa chica del cerro Neblina & & & & & & & & 1 & 1 & & & & & \\
\hline 25 & Marmosops noctivagus (Tschudi, 1844) & Comadrejita marsupial noctámbula & & 1 & & & & & & 1 & 1 & 1 & & & & \\
\hline 26 & Metachirus nudicaudatus (É. Geoffroy, 1803) & Rata marsupial de cuatro ojos & & & & & & & & 1 & 1 & & & & & \\
\hline & Monodelphis adusta (Thomas, 1897) & Marsupial sepia de cola corta & & & & & & & & & 1 & & & & & \\
\hline 28 & Monodelphis emiliae (Thomas, 1912) & Colicorto marsupial de Emilia & & & & & & & & & 1 & & & & & \\
\hline & Monodelphis glirina (Wagner, 1842) & Colicorto de flancos rojos & & & & & & & & & 1 & & & & & \\
\hline & Monodelphis handleyi Solari, 2007 & Colicorto marsupial de Handley & & & & & & & & & 1 & & 1 & & & \\
\hline 31 & Monodelphis osgoodi Doutt, 1938 & Colicorto marsupial de Osgood & & & & & & & & 1 & & & & & & $\mathrm{VU}$ \\
\hline & Monodelphis peruviana (Osgood, 1913) & Colicorto marsupial peruano & & & & & & & & 1 & 1 & & & & & \\
\hline & Monodelphis ronaldi Solari, 2004 & Colicorto marsupial de Ronald & & & & & & & & & 1 & & 1 & & & \\
\hline 34 & Monodelphis sp. & & & & & & & & & 1 & & & 1 & & & \\
\hline & Philander andersoni (Osgood, 1913) & Zarigüeyita negra de Anderson & & & & & & & & & 1 & & & & & \\
\hline & Philander mcilhennyi Gardner y Patton, 1972 & Zarigüeyita de cola poblada & & & & & & & & & 1 & & & & & \\
\hline & Philander opossum (Linnaeus, 1758) & Zarigüeyita gris de cuatro ojos & & & & & & & & 1 & 1 & 1 & & & & \\
\hline & Thylamys pallidior (Thomas, 1902) & $\begin{array}{l}\text { Marmosa coligruesa de vientre } \\
\text { blanco }\end{array}$ & & & & & & & 1 & & & & & & & \\
\hline 39 & Thylamys tatei (Handley, 1957) & Marmosa coligruesa de Tate & & & & 1 & 1 & & & & & & 1 & & & \\
\hline
\end{tabular}


Diversidad de los mamíferos del Perú

\begin{tabular}{|c|c|c|c|c|c|c|c|c|c|c|c|c|c|}
\hline Thylamys sp. & & & & 1 & 1 & & & & & 1 & & & \\
\hline \multicolumn{14}{|l|}{ Paucituberculata } \\
\hline \multicolumn{14}{|l|}{ Caenolestidae } \\
\hline Caenolestes caniventer Anthony, 1921 & Musaraña marsupial de vientre gris & & & & & 1 & 1 & & & & & & \\
\hline 42 Lestoros inca (Thomas, 1917) & Musaraña marsupial incaica & & & & & & 1 & & & & & & \\
\hline \multicolumn{14}{|l|}{ Sirenia } \\
\hline \multicolumn{14}{|l|}{ Trichechidae } \\
\hline 43 Trichechus inunguis (Natterer, 1883) & Manatí & & & & & & & 1 & & & $\mathrm{VU}$ & $\mathrm{I}$ & EN \\
\hline \multicolumn{14}{|l|}{ Cingulata } \\
\hline \multicolumn{14}{|l|}{ Dasypodidae } \\
\hline $44 \quad$ Dasypus kappleri Krauss, 1862 & Armadillo de Kappler & & & & & & & 1 & & & & & \\
\hline Dasypus novemcinctus Linnaeus, 1758 & $\begin{array}{l}\text { Armadillo de nueve bandas, } \\
\text { carachupa }\end{array}$ & 1 & & & & & 1 & 1 & & & & & \\
\hline Dasypus pilosus (Fitzinger, 1856) & Armadillo peludo & & & & & & 1 & & & 1 & $\mathrm{VU}$ & & $\mathrm{Vu}$ \\
\hline 47 Dasypus septemcinctus Linnaeus, 1758 & Armadillo de siete bandas & & & & & & & & 1 & & & & \\
\hline $48 \quad$ Cabassous unicinctus (Linnaeus, 1758) & Armadillo de cola desnuda & & & & & & & 1 & & & & & \\
\hline $49 \quad$ Priodontes maximus (Kerr, 1792) & $\begin{array}{l}\text { Armadillo gigante, tatú, carachupa, } \\
\text { yungunturu, kinterro }\end{array}$ & & & & & & & 1 & 1 & & $\mathrm{VU}$ & $\mathrm{I}$ & $\mathrm{Vu}$ \\
\hline \multicolumn{14}{|l|}{ Pilosa } \\
\hline \multicolumn{14}{|l|}{ Bradypodidae } \\
\hline $50 \quad$ Bradypus variegatus Schinz, 1825 & Perezoso de tres dedos, pelejo & 1 & & & & & 1 & 1 & & & & II & \\
\hline \multicolumn{14}{|l|}{ Megalonychidae } \\
\hline $51 \quad$ Choloepus didactylus (Linnaeus, 1758) & Perezoso de dos dedos, pelejo & & & & & & 1 & 1 & & & & & \\
\hline 52 Choloepus hoffmanni Peters, 1858 & $\begin{array}{l}\text { Perezoso de dos dedos de Hoffmann, } \\
\text { pelejo }\end{array}$ & 1 & & & & & 1 & 1 & & & & III & \\
\hline \multicolumn{14}{|l|}{ Cyclopedidae } \\
\hline $53 \quad$ Cyclopes didactylus (Linnaeus, 1758) & Serafín, intepelejo & & & & & & 1 & 1 & & & & & \\
\hline \multicolumn{14}{|l|}{ Myrmecophagidae } \\
\hline $54 \quad$ Myrmecophaga tridactyla Linnaeus, 1758 & Oso hormiguero, oso bandera, shiani & & & & & & & 1 & 1 & & & II & $\mathrm{Vu}$ \\
\hline Tamandua mexicana (Saussure, 1860) & Oso hormiguero norteño & 1 & 1 & 1 & & & & & & & & III & \\
\hline $56 \quad$ Tamandua tetradactyla (Linnaeus, 1758) & $\begin{array}{l}\text { Oso hormiguero amazónico, shihui, } \\
\text { osito colmenero, tamandúa, capaire }\end{array}$ & & & & & & 1 & 1 & & & & & \\
\hline \multicolumn{14}{|l|}{ Primates } \\
\hline \multicolumn{14}{|l|}{ Cebidae } \\
\hline 57 Callimico goeldii (Thomas, 1904) & Pichico falso de Goeldi & & & & & & & 1 & & & $\mathrm{VU}$ & $\mathrm{I}$ & $\mathrm{vu}$ \\
\hline Callithrix pygmaea (Spix, 1823) & $\begin{array}{l}\text { Tití enano, chichico, leoncito o mono } \\
\text { de bolsillo }\end{array}$ & & & & & & & 1 & & & & II & \\
\hline Saguinus fuscicollis (Spix, 1823) & Pichico común, pichico & & & & & & & 1 & 1 & & & II & \\
\hline Saguinus graellsi (Jiménez de la Espada, 1870) & Pichico del Napo & & & & & & & 1 & & & & II & \\
\hline 61 Saguinus imperator (Goeldi, 1907) & Pichico emperador & & & & & & & 1 & & & & II & \\
\hline Saguinus labiatus (É. Geoffroy, 1812) & Pichico de barriga anaranjada & & & & & & & 1 & & & & II & EN \\
\hline Saguinus mystax (Spix, 1823) & Pichico de bigote o de barba blanca & & & & & & & 1 & & & & II & \\
\hline Saguinus nigricollis (Spix, 1823) & Pichico de cuello negro & & & & & & & 1 & & & & II & \\
\hline Saguinus tripartitus (Milne-Edwards, 1878) & Pichico de manto dorado & & & & & & & 1 & & & & II & \\
\hline Aotus azarae (Humboldt, 1811) & Mono nocturno de Azara & & & & & & & 1 & & & & II & \\
\hline Aotus miconax Thomas, 1927 & Mono nocturno peruano & & & & & & 1 & 1 & & 1 & $\mathrm{VU}$ & II & EN \\
\hline Aotus nancymaae Hershkovitz, 1983 & Mono nocturno de Nancy & & & & & & & 1 & & & & II & \\
\hline 69 Aotus nigriceps Dollman, 1909 & Mono nocturno cabecinegro & & & & & & 1 & 1 & & & & II & \\
\hline $70 \quad$ Aotus vociferans (Spix, 1823) & $\begin{array}{l}\text { Mono nocturno vociferante, buri- } \\
\text { buri }\end{array}$ & & & & & & & 1 & & & & II & \\
\hline Cebus albifrons (Humboldt, 1812) & $\begin{array}{l}\text { Machín frontiblanco, machín blanco, } \\
\text { mono blanco, makieri }\end{array}$ & 1 & & & & & 1 & 1 & & & & II & \\
\hline $72 \quad$ Cebus apella (Linnaeus, 1758) & $\begin{array}{l}\text { Machín, machín capuchino, machín } \\
\text { negro, mono negro, koshiri }\end{array}$ & & & & & & 1 & 1 & 1 & & & II & \\
\hline
\end{tabular}


Pacheco et al.

\begin{tabular}{|c|c|c|c|c|c|c|c|c|c|c|c|c|c|c|}
\hline 73 & Cebus libidinosus Spix, 1823 & Mono silbador & & & & & & & 1 & & & & II & \\
\hline 74 & $\begin{array}{l}\text { Saimiri boliviensis (I.Geoffroy y Blainville, } \\
\text { 1834) }\end{array}$ & Mono fraile boliviano, frailecillo & & & & & & & 1 & & & & II & \\
\hline 75 & Saimiri sciureus (Linnaeus, 1758) & Mono ardilla, ciyéri & & & & & & 1 & 1 & 1 & & & II & \\
\hline \multicolumn{15}{|c|}{ Pitheciidae } \\
\hline & $\begin{array}{l}\text { Callicebus aureipalatii Wallace, Gómez, A. } \\
\text { Felton \& A. M. Felton, } 2006\end{array}$ & Tocón del Madidi & & & & & & & 1 & & & & II & \\
\hline 77 & Callicebus brunneus (Wagner, 1842) & Tocón moreno & & & & & & & 1 & & & & II & \\
\hline 78 & Callicebus cupreus (Spix, 1823) & Tocón cobrizo & & & & & & & 1 & & & & II & \\
\hline 79 & Callicebus discolor (I. Geoffroy y Deville, 1848) & Cotoncillo rojo & & & & & & & 1 & & & & II & \\
\hline 80 & Callicebus lucifer Thomas, 1914 & Tocón de collar & & & & & & & 1 & & & & II & $\mathrm{Vu}$ \\
\hline 81 & Callicebus oenanthe Thomas, 1924 & Tocón del río Mayo & & & & & & & 1 & & 1 & EN & II & $\mathrm{Vu}$ \\
\hline 82 & Cacajao calvus (I. Geoffroy, 1847) & $\begin{array}{l}\text { Mono inglés, huapo colorado, puca } \\
\text { huapo }\end{array}$ & & & & & & & 1 & & & $\mathrm{VU}$ & $\mathrm{I}$ & $\mathrm{Vu}$ \\
\hline 83 & Pithecia aequatorialis Hershkovitz, 1987 & Huapo ecuatorial & & & & & & & 1 & & & & II & \\
\hline 84 & Pithecia irrorata Gray, 1842 & Huapo de Gray & & & & & & & 1 & & & & II & \\
\hline 85 & Pithecia monachus (É. Geoffroy, 1812) & Huapo negro, yana huapo & & & & & & & 1 & & & & II & \\
\hline \multicolumn{15}{|c|}{ Atelidae } \\
\hline 86 & Alouatta juara Elliot, 1910 & Mono aullador del Juruá & & & & & & & 1 & & & & II & \\
\hline 87 & Alouatta palliata (Gray, 1849) & $\begin{array}{l}\text { Mono aullador con manto, coto } \\
\text { negro }\end{array}$ & 1 & & & & & & & & & & $\mathrm{I}$ & EN \\
\hline 88 & Alouatta puruensis Lönnberg, 1941 & Mono aullador rojo del Purús & & & & & & & 1 & & & & II & \\
\hline 89 & Alouatta sara Elliot, 1910 & Mono aullador rojo boliviano & & & & & & 1 & 1 & 1 & & & II & \\
\hline 90 & Ateles belzebuth É. Geoffroy, 1806 & $\begin{array}{l}\text { Mono araña grisáceo, maquisapa, } \\
\text { koshíri, iempari }\end{array}$ & & & & & & 1 & 1 & & & EN & II & EN \\
\hline 91 & Ateles chamek (Humboldt, 1812) & $\begin{array}{l}\text { Mono araña negro, maquisapa, } \\
\text { covéro, oshéto }\end{array}$ & & & & & & 1 & 1 & 1 & & EN & II & $\mathrm{Vu}$ \\
\hline 92 & Lagothrix cana (É. Geoffroy, 1812) & Mono lanudo gris & & & & & & 1 & 1 & & & EN & II & $\mathrm{Vu}$ \\
\hline 93 & Lagothrix flavicauda (Humboldt, 1812) & Mono choro de cola amarilla & & & & & & 1 & & & 1 & $\mathrm{CR}$ & $\mathrm{I}$ & EN \\
\hline 94 & Lagothrix lagotricha (Humboldt, 1812) & $\begin{array}{l}\text { Mono choro común, kamarári, } \\
\text { kumaginaro }\end{array}$ & & & & & & & 1 & & & $\mathrm{VU}$ & II & $\mathrm{Vu}$ \\
\hline 95 & Lagothrix poeppigii Schinz, 1844 & Mono lanudo de Pöppig & & & & & & & 1 & & & $\mathrm{VU}$ & II & \\
\hline \multicolumn{15}{|c|}{ Rodentia } \\
\hline \multicolumn{15}{|c|}{ Sciuridae } \\
\hline & Sciurillus pusillus (E. Geoffroy, 1803) & Ardillita neotropical de Buffon & & & & & & & 1 & & & & & \\
\hline 97 & Microsciurus flaviventer (Gray, 1867) & Ardillita de vientre amarillo & & & & & & 1 & 1 & & & & & \\
\hline 98 & Microsciurus sp. & & & & & & & 1 & & & 1 & & & \\
\hline 99 & Sciurus ignitus (Gray, 1867) & Ardilla ígnia & & & & & & 1 & 1 & 1 & & & & \\
\hline 100 & Sciurus igniventris Wagner, 1842 & Ardilla de vientre rojo & & & & & & & 1 & & & & & \\
\hline 101 & Sciurus pyrrhinus Thomas, 1898 & Ardilla rojiza & & & & & & 1 & 1 & & 1 & & & $\mathrm{Vu}$ \\
\hline 102 & Sciurus sanborni Osgood, 1944 & Ardilla de Sanborn & & & & & & & 1 & 1 & 1 & & & $\mathrm{VU}$ \\
\hline 103 & Sciurus spadiceus Olfers, 1818 & Ardilla baya & & & & & & 1 & 1 & 1 & & & & \\
\hline & Sciurus stramineus Eydoux y Souleyet, 1841 & Ardilla nuca blanca & 1 & 1 & 1 & 1 & & & & & & & & \\
\hline \multicolumn{15}{|c|}{ Cricetidae } \\
\hline 105 & Abrothrix andinus (Philippi, 1858) & Ratón campestre andino & & & & 1 & 1 & & & & & & & \\
\hline 106 & Abrothrix jelskii (Thomas, 1894) & $\begin{array}{l}\text { Ratón campestre de jelski, allqa- } \\
\text { jukucha }\end{array}$ & & & & & 1 & & & & & & & \\
\hline 107 & Aegialomys xantheolus (Thomas, 1894) & Ratón arrozalero amarillento & 1 & 1 & 1 & 1 & & & & & & & & \\
\hline 108 & Akodon aerosus Thomas, 1913 & Ratón campestre cobrizo & & & & & & 1 & 1 & & & & & \\
\hline 109 & Akodon albiventer Thomas, 1897 & Ratón campestre de vientre blanco & & & & & 1 & & & & & & & \\
\hline 110 & Akodon boliviensis Meyen, 1833 & Ratón campestre boliviano & & & & & 1 & & & & & & & \\
\hline 111 & Akodon fumeus Thomas, 1902 & Ratón campestre ahumado & & & & & & 1 & & & & & & \\
\hline & $\begin{array}{l}\text { Akodon juninensis Myers, Patton, y Smith, } \\
1990\end{array}$ & Ratón campestre de Junín & & & & 1 & 1 & & & & 1 & & & \\
\hline & Akodon kofordi Myers y Patton, 1989 & Ratón campestre de Koford & & & & & & 1 & & & & & & \\
\hline
\end{tabular}


Diversidad de los mamíferos del Perú

\begin{tabular}{|c|c|c|c|c|c|c|c|c|c|c|c|c|c|}
\hline 114 & Akodon lutescens J.A. Allen, 1901 & Ratón campestre chico & & & & & 1 & & & & & & \\
\hline 115 & Akodon mimus (Thomas, 1901) & Ratón campestre colilargo & & & & & & 1 & & & & & \\
\hline 116 & Akodon mollis Thomas, 1894 & Ratón campestre de pelo suave & & 1 & 1 & 1 & 1 & & & & & & \\
\hline 117 & Akodon orophilus Osgood, 1913 & Ratón campestre montañés & & & & & & 1 & & & 1 & & \\
\hline 118 & Akodon subfuscus Osgood, 1944 & Ratón campestre moreno & & & 1 & & 1 & & & & & & \\
\hline 119 & Akodon surdus Thomas, 1917 & Ratón campestre de vientre pizarra & & & & & & 1 & & & 1 & $\mathrm{VU}$ & \\
\hline 120 & Akodon torques (Thomas, 1917) & Ratón campestre de bosque montano & & & & & & 1 & & & 1 & & \\
\hline 121 & Akodon sp. & & & & & & 1 & & & & 1 & & \\
\hline 122 & Amphinectomys savamis Malygin, 1994 & Ratón acuático de Ucayali & & & & & & & 1 & & 1 & & \\
\hline 123 & Andinomys edax Thomas, 1902 & Rata andina voraz & & & & & 1 & & & & & & \\
\hline 124 & Auliscomys boliviensis (Waterhouse, 1846) & Ratón orejón boliviano & & & & & 1 & & & & & & \\
\hline 125 & Auliscomys pictus (Thomas, 1884) & Ratón orejón pintado & & & & & 1 & & & & & & \\
\hline 126 & Auliscomys sublimis (Thomas, 1900) & Ratón orejón sublime & & & & & 1 & & & & & & \\
\hline 127 & Calomys lepidus (Thomas, 1884) & Ratón vespertino precioso & & & & & 1 & & & & & & \\
\hline 128 & Calomys sorellus (Thomas, 1900) & Ratón vespertino rojizo & & & 1 & & 1 & & & & 1 & & \\
\hline 129 & $\begin{array}{l}\text { Cerradomys maracajuensis (Langguth y } \\
\text { Bonvicino, 2002) }\end{array}$ & & & & & & & & 1 & 1 & & & \\
\hline 130 & Chibchanomys trichotis (Thomas, 1897) & Rata chibcha de oreja peluda & & & & & & 1 & & & & & $\mathrm{VU}$ \\
\hline 131 & Chinchillula sahamae Thomas, 1898 & Ratón chinchilla del Sajama & & & & & 1 & & & & & & \\
\hline 132 & Eligmodontia hirtipes (Thomas, 1902) & Laucha colilarga, laucha de la puna. & & & & & 1 & & & & & & \\
\hline 133 & Eremoryzomys polius (Osgood, 1913) & Ratón arrozalero de Osgood & & & & & & 1 & & & 1 & & \\
\hline 134 & Euryoryzomys macconnelli (Thomas, 1910) & Ratón arrozalero de Macconel & & & & & & 1 & 1 & & & & \\
\hline 135 & Euryoryzomys nitidus (Thomas, 1884) & Ratón arrozalero lustroso & & & & & & & 1 & & & & \\
\hline 136 & Galenomys garleppi (Thomas, 1898) & Ratón orejón de Garlepp & & & & & 1 & & & & & & \\
\hline 137 & Holochilus sciureus Wagner, 1842 & Rata ardilla de pantano & & & & & & & 1 & & & & \\
\hline 138 & Hylaeamys perenensis (J. A. Allen, 1901) & Ratón arrozalero cabezudo & & & & & & & 1 & & & & \\
\hline 139 & Hylaeamys yunganus (Thomas, 1902) & Ratón arrozalero de la yungas & & & & & & 1 & 1 & & & & \\
\hline 140 & Ichthyomys stolzmanni Thomas, 1893 & Rata pescadora & & & & & & 1 & & & & & \\
\hline 141 & Lenoxus apicalis (J. A. Allen, 1900) & Rata andina & & & & & & 1 & & & & & \\
\hline 142 & Melanomys caliginosus (Tomes, 1860) & Ratón arrocero oscuro & 1 & & & & & & & & & & \\
\hline 143 & Melanomys robustulus Thomas, 1914 & Ratón arrocero negro robusto & & & & & & & 1 & & & & \\
\hline 144 & Melanomys zunigae (Sanborn, 1949) & Ratón arrozalero de Zúñiga & & 1 & & & & & & & 1 & $\mathrm{CR}$ & $\mathrm{CR}$ \\
\hline 145 & Microryzomys altissimus (Osgood, 1933) & Ratoncito arrozalero de altitud & & & & 1 & 1 & 1 & & & & & \\
\hline 146 & Microryzomys minutus (Tomes, 1860) & Ratoncito arrozalero diminuto & & & & 1 & & 1 & & & & & \\
\hline 147 & $\begin{array}{l}\text { Neacomys minutus Patton, da Silva, y } \\
\text { Malcolm, } 2000\end{array}$ & Ratón espinoso pequeño & & & & & & & 1 & & & & \\
\hline 148 & $\begin{array}{l}\text { Neacomys musseri Patton, da Silva, y Malcolm, } \\
2000\end{array}$ & Ratón espinoso de Musser & & & & & & 1 & 1 & & & & \\
\hline 149 & Neacomys spinosus (Thomas, 1882) & Ratón espinoso común & & & & & & 1 & 1 & & & & \\
\hline 150 & Necromys amoenus (Thomas, 1900) & Ratón campestre hermoso & & & & & 1 & & & & & & \\
\hline 151 & Necromys lenguarum (Thomas, 1898) & Ratón bayo & & & & & & & 1 & 1 & & & \\
\hline 152 & Nectomys apicalis Peters, 1861 & Nectomys de la Amazonía occidental & & & & & & 1 & 1 & & & & \\
\hline 153 & Nectomys rattus (Pelzeln, 1883) & Nectomys amazónico & & & & & & & 1 & & & & \\
\hline 154 & Neotomys ebriosus Thomas, 1894 & Ratón de humedales andino & & & & & 1 & & & & & & \\
\hline 155 & Nephelomys albigularis (Tomes, 1860) & Ratón arrozalero de cuello blanco & & & & 1 & & 1 & & & & & \\
\hline 156 & Nephelomys auriventer (Thomas, 1890) & Ratón arrozalero de vientre dorado & & & & & & 1 & & & & & \\
\hline 157 & Nephelomys keaysi (J. A. Allen, 1900) & Ratón arrozalero de las yungas & & & & & & 1 & & & & & \\
\hline 158 & Nephelomys levipes (Thomas, 1902) & Ratón arrozalero de patas claras & & & & & & 1 & & & & & \\
\hline 159 & $\begin{array}{l}\text { Neusticomys peruviensis (Musser y Gardner, } \\
1974 \text { ) }\end{array}$ & Rata acuática peruana & & & & & & & 1 & & 1 & & $\mathrm{U}$ \\
\hline
\end{tabular}


Pacheco et al.

\begin{tabular}{|c|c|c|c|c|c|c|c|c|c|c|c|c|c|}
\hline 160 & Oecomys bicolor (Tomes, 1860) & Ratón arrozalero bicolor & & & & & & & & 1 & 1 & & \\
\hline 161 & Oecomys phaeotis (Thomas, 1901) & Ratón arrozalero pardo & & & & & & & 1 & & 1 & & \\
\hline 162 & Oecomys roberti (Thomas, 1904) & Ratón arrozalero amazónico & & & & & & & & 1 & & & \\
\hline 163 & Oecomys superans Thomas, 1911 & Ratón arrozalero selvático & & & & & & & & 1 & & & \\
\hline 164 & $\begin{array}{l}\text { Oecomys trinitatis (J. A. Allen y Chapman, } \\
1893 \text { ) }\end{array}$ & Ratón arrozalero peludo & & & & & & & & 1 & & & \\
\hline 165 & Oligoryzomys andinus (Osgood, 1914) & Ratón arrozalero andino & & & & 1 & & 1 & 1 & & & & \\
\hline 166 & Oligoryzomys arenalis (Thomas, 1913) & Ratón arrozalero de los arenales & & & 1 & 1 & & & & & 1 & & \\
\hline 167 & Oligoryzomys destructor (Tschudi, 1844) & Ratón arrozalero destructor & & & & & & & 1 & 1 & & & \\
\hline 168 & Oligoryzomys microtis (J. A. Allen, 1916) & Ratón arrozalero de oreja pequeña & & & & & & & & 1 & & & \\
\hline 169 & Oligoryzomys sp.B & & & & & & & 1 & 1 & & & & \\
\hline 170 & Oligoryzomys sp.C & & & & & & & & 1 & & 1 & & \\
\hline 171 & Oreoryzomys balneator (Thomas, 1900) & Ratón arrozalero ecuatoriano & & & & & 1 & & 1 & & & & \\
\hline 172 & $\begin{array}{l}\text { Oxymycterus hiska Hinojosa, Anderson y } \\
\text { Patton, } 1987\end{array}$ & Ratón hocicudo menor & & & & & & & 1 & & & & $\mathrm{VU}$ \\
\hline 173 & Oxymycterus inca Thomas, 1900 & Ratón hocicudo Inca & & & & & & & 1 & 1 & & & \\
\hline 174 & Oxymycterus paramensis Thomas, 1902 & Hocicudo parameño & & & & & & 1 & & & & & \\
\hline 175 & Phyllotis amicus (Thomas, 1900) & Ratón orejón amigo & & 1 & 1 & 1 & & & & & 1 & & \\
\hline 176 & Phyllotis andium Thomas, 1912 & Ratón orejón andino & & & 1 & 1 & 1 & 1 & & & & & \\
\hline 177 & Phyllotis definitus Osgood, 1915 & Ratón orejón definido & & & & 1 & & 1 & & & 1 & EN & \\
\hline 178 & Phyllotis gerbillus Thomas, 1900 & Ratón orejón gerbito & & 1 & & & & & & & 1 & & \\
\hline 179 & Phyllotis limatus Thomas, 1912 & Ratón orejón de Lima & & & 1 & 1 & & 1 & & & & & \\
\hline 180 & Phyllotis magister Thomas, 1912 & Ratón orejón maestro & & & & 1 & & 1 & & & & & \\
\hline 181 & Phyllotis osilae J. A. Allen, 1901 & Ratón orejón de Asillo & & & & & & 1 & & & & & \\
\hline 182 & Phyllotis xanthopygus (Waterhouse, 1837) & Ratón orejón de ancas amarillentas & & & & 1 & & 1 & & & & & \\
\hline 183 & Phyllotis sp. & Ratón orejón & & & & & & 1 & & & 1 & . & \\
\hline 184 & Pseudoryzomys simplex (Winge, 1887) & Falso ratón arrozalero del Brasil & & & & & & & & 1 & & & \\
\hline 185 & Punomys kofordi Pacheco y Patton, 1995 & Ratón puneño de Koford & & & & & & 1 & & & 1 & $\mathrm{VU}$ & \\
\hline 186 & Punomys lemminus Osgood, 1943 & Ratón puneño & & & & & & 1 & & & 1 & $\mathrm{VU}$ & \\
\hline 187 & Rhagomys longilingua Luna y Patterson, 2003 & Rhagomys de lengua larga & & & & & & & 1 & 1 & & & \\
\hline 188 & $\begin{array}{l}\text { Rhipidomys gardneri Patton, da Silva, y } \\
\text { Malcom, } 2000\end{array}$ & Rata trepadora de Gardner & & & & & & & 1 & 1 & & & \\
\hline 189 & Rhipidomys leucodactylus (Tschudi, 1845) & Rata de las Chirimoyas & 1 & 1 & & 1 & & & 1 & 1 & & & \\
\hline 190 & Rhipidomys modicus Thomas, 1926 & Rata trepadora peruana & & & & & & & 1 & 1 & 1 & & \\
\hline 191 & Rhipidomys ochrogaster J. A. Allen, 1901 & Rata trepadora de vientre ocre & & & & & & & 1 & & 1 & & $\mathrm{Vu}$ \\
\hline 192 & Scolomys melanops Anthony, 1924 & Ratón espinoso ecuatoriano & & & & & & & & 1 & & & \\
\hline 193 & Scolomys ucayalensis Pacheco, 1991 & Ratón espinoso del Ucayali & & & & & & & & 1 & & & \\
\hline 194 & Sigmodon peruanus J. A. Allen, 1897 & Rata peluda peruana & 1 & 1 & 1 & & & & & & & & \\
\hline 195 & Thomasomys apeco Leo L. y Gardner, 1993 & Ratón montaraz de Apeco & & & & & & & 1 & & 1 & $\mathrm{VU}$ & $\mathrm{Vu}$ \\
\hline 196 & Thomasomys aureus (Tomes, 1860) & Ratón montaraz dorado & & & & & 1 & & 1 & & & & \\
\hline 197 & Thomasomys caudivarius Anthony, 1923 & Ratón montaraz de cola variada & & & & & & & 1 & & & & \\
\hline 198 & Thomasomys cinereus (Thomas, 1882) & Ratón montaraz ceniciento & & & & 1 & 1 & & 1 & & 1 & & \\
\hline 199 & Thomasomys daphne Thomas, 1917 & Ratón montaraz de Dafne & & & & & & & 1 & & & & \\
\hline 200 & Thomasomys eleusis Thomas, 1926 & Ratón montaraz peruano & & & & & & & 1 & & 1 & & \\
\hline 201 & Thomasomys gracilis Thomas, 1917 & Ratón montaraz delicado & & & & & & & 1 & & 1 & & $\mathrm{VU}$ \\
\hline 202 & Thomasomys incanus (Thomas, 1894) & Ratón montaraz incaico & & & & & & 1 & 1 & & 1 & $\mathrm{VU}$ & $\mathrm{Vu}$ \\
\hline 203 & Thomasomys ischyrus Osgood, 1914 & Ratón montaraz de Amazonas & & & & & & 1 & 1 & & 1 & $\mathrm{VU}$ & \\
\hline 204 & Thomasomys kalinowskii (Thomas, 1894) & Ratón montaraz de kalinowski & & & & & & & 1 & & 1 & $\mathrm{VU}$ & $\mathrm{Vu}$ \\
\hline 205 & $\begin{array}{l}\text { Thomasomys macrotis Gardner y Romo R., } \\
1993\end{array}$ & Ratón montaraz orejón & & & & & & & 1 & & 1 & $\mathrm{VU}$ & $\mathrm{VU}$ \\
\hline
\end{tabular}


Diversidad de los mamíferos del Perú

\begin{tabular}{|c|c|c|c|c|c|c|c|c|c|c|c|c|c|c|}
\hline 206 & Thomasomys notatus Thomas, 1917 & Ratón montaraz marcado & & & & & & 1 & & & 1 & & & \\
\hline 207 & Thomasomys onkiro Luna y Pacheco, 2002 & Ratón montaraz ashaninka & & & & & & 1 & & & 1 & VU & & $\mathrm{VU}$ \\
\hline 208 & Thomasomys oreas Anthony, 1926 & Ratón montaraz dorado pequeño & & & & & & 1 & & & & & & \\
\hline 209 & Thomasomys praetor (Thomas, 1900 ) & Ratón montaraz de Cajamarca & & & 1 & & & & & & 1 & & & $\mathrm{VU}$ \\
\hline 210 & Thomasomys pyrrhonotus Thomas, 1886 & Ratón montaraz de dorso rojizo & & & 1 & 1 & & 1 & & & 1 & $\mathrm{VU}$ & & EN \\
\hline 211 & $\begin{array}{l}\text { Thomasomys rosalinda Thomas y St. Leger, } \\
1926\end{array}$ & Ratón montaraz rosalinda & & & & & & 1 & & & 1 & & & EN \\
\hline 212 & Thomasomys taczanowskii (Thomas, 1882) & Ratón montaraz de Taczanowski & & & 1 & 1 & & 1 & & & 1 & & & $\mathrm{vu}$ \\
\hline 213 & Transandinomys talamancae (J. A. Allen, 1891) & Ratón arrozalero de Talamanca & 1 & & & & & & & & & & & \\
\hline \multicolumn{15}{|c|}{ Erethizontidae } \\
\hline 214 & Coendou bicolor (Tschudi, 1844) & $\begin{array}{l}\text { Puerco espín arborícola, erizo, casha } \\
\text { cushillo, tontóri }\end{array}$ & & & & & & 1 & 1 & & & & & \\
\hline 215 & Coendou ichillus (Voss y da Silva, 2001) & Puerco espín pequeño ecuatoriano & & & & & & & 1 & & & & & \\
\hline 216 & Coendou prehensilis (Linnaeus, 1758) & Puerco espín brasileño & & & & & & & 1 & & & & & \\
\hline 217 & Echinoprocta rufescens Gray, 1865 & Puerco espín de cola corta & & & 1 & & & 1 & & & & & & \\
\hline \multicolumn{15}{|c|}{ Chinchillidae } \\
\hline 218 & Chinchilla chinchilla (Lichtenstein, 1829) & Chinchilla & & & & & 1 & & & & & CR & $\mathrm{I}$ & $\mathrm{CR}$ \\
\hline 219 & Lagidium peruanum Meyen, 1833 & Viscacha peruana, uisk'acha & & 1 & 1 & & 1 & 1 & & & & & & \\
\hline 220 & Lagidium viscacia (Molina, 1782) & Viscacha chilena & & & 1 & & 1 & & & & & & & \\
\hline \multicolumn{15}{|c|}{ Dinomyidae } \\
\hline 221 & Dinomys branickii Peters, 1873 & $\begin{array}{l}\text { Machetero, pacarana, picuru maman, } \\
\text { gopi }\end{array}$ & & & & & & 1 & 1 & & & VU & & EN \\
\hline \multicolumn{15}{|c|}{ Caviidae } \\
\hline & Cavia aperea Erxleben, 1777 & Cuy silvestre brasileño & & & & & & & & 1 & & & & \\
\hline & Cavia porcellus (Linnaeus, 1758) & $\begin{array}{l}\text { Cuy doméstico, cochinillo de Indias, } \\
\text { cavias, ccoe, k'itaccoe }\end{array}$ & & & 1 & & 1 & & & & & & & \\
\hline 224 & Cavia tschudii Fitzinger, 1857 & Cuy silvestre & & 1 & 1 & & 1 & & & & & & & \\
\hline & Galea musteloides Meyen, 1832 & Sasha-cuy & & & & & 1 & & & & & & & \\
\hline & Hydrochoerus hydrochaeris (Linnaeus, 1766) & Ronsoco, ivéto & & & & & & & 1 & 1 & & & & \\
\hline \multicolumn{15}{|c|}{ Dasyproctidae } \\
\hline & Dasyprocta fuliginosa Wagler, 1832 & Añuje, chapana, cutpe & & & & & & 1 & 1 & & & & & \\
\hline & Dasyprocta kalinowskii Thomas, 1897 & Sihuro, añuje, cutpe, agutí & & & & & & 1 & & & 1 & & & \\
\hline & Dasyprocta variegata Tschudi, 1845 & Añuje, cutpe, agutí & & & & & & 1 & 1 & 1 & & & & \\
\hline & Myoprocta pratti Pocock, 1913 & Punchana, añuje menor & & & & & & & 1 & & & & & \\
\hline \multicolumn{15}{|c|}{ Cuniculidae } \\
\hline & Cuniculus paca (Linnaeus, 1766) & Majaz, picuro,zamaño, liebre, samani & & & & & & 1 & 1 & & & & III & \\
\hline & Cuniculus taczanowskii (Stolzmann, 1865) & $\begin{array}{l}\text { Paca de Taczanowski, majaz de } \\
\text { montaña }\end{array}$ & & & & 1 & & 1 & & & & & & $\mathrm{vu}$ \\
\hline \multicolumn{15}{|c|}{ Ctenomyidae } \\
\hline & Ctenomys leucodon Waterhouse, 1848 & Tucu-tucu de dientes blancos & & & & & 1 & & & & & & & \\
\hline & Ctenomys opimus Wagner, 1848 & Tucu-tucu del Titicaca & & & 1 & & 1 & & & & & & & \\
\hline & Ctenomys peruanus Sanborn y Pearson, 1947 & Tucu-tucu peruano & & & & & 1 & & & & 1 & & & \\
\hline \multicolumn{15}{|c|}{ Abrocomidae } \\
\hline & Abrocoma cinerea Thomas, 1919 & Rata chinchilla cenicienta & & & & & 1 & & & & & & & \\
\hline & Cuscomys ashaninka Emmons, 1999 & Rata chinchilla arborícola ashaninka & & & & & & 1 & & & 1 & & & \\
\hline 238 & Cuscomys oblativus (Eaton, 1916) & $\begin{array}{l}\text { Rata chinchilla arborícola de Machu } \\
\text { Picchu }\end{array}$ & & & & & & 1 & & & 1 & EX & & \\
\hline \multicolumn{15}{|c|}{ Echimyidae } \\
\hline 239 & Dactylomys boliviensis Anthony, 1920 & Cono-cono boliviano & & & & & & 1 & 1 & & & & & \\
\hline 240 & Dactylomys dactylinus (Desmarest, 1817) & Cono-cono amazónico & & & & & & & 1 & & & & & \\
\hline 241 & Dactylomys peruanus J. A. Allen, 1900 & Cono-cono peruano & & & & & & 1 & & & & & & \\
\hline & Echimys saturnus Thomas, 1928 & Rata de espinas oscuras & & & & & & & 1 & & & & & \\
\hline
\end{tabular}


Pacheco et al.

\begin{tabular}{|c|c|c|c|c|c|c|c|c|c|c|c|c|c|}
\hline 243 & $\begin{array}{l}\text { Isothrix barbarabrownae Patterson y Velazco, } \\
2006\end{array}$ & Toró de Barbara Brown & & & & & & 1 & & & 1 & & \\
\hline 244 & Isothrix bistriata Wagner, 1845 & $\begin{array}{l}\text { Rata de doble estría, coconocono, } \\
\text { toró }\end{array}$ & & & & & & & 1 & & & & \\
\hline 245 & Makalata macrura (Wagner, 1842) & Rata espinosa de árbol & & & & & & & 1 & & & & \\
\hline 246 & Makalata rhipidura (Thomas, 1928) & Rata espinosa peruana & & & & & & & 1 & & 1 & & \\
\hline 247 & Pattonomys occasius (Thomas, 1921) & Rata arborícola de cola desnuda & & & & & & 1 & 1 & & & & \\
\hline 248 & Mesomys hispidus (Desmarest, 1817) & Rata espinosa áspera de río Madeira & & & & & & & 1 & 1 & & & \\
\hline 249 & Mesomys leniceps Thomas y St. Leger, 1926 & Rata espinosa áspera peruana & & & & & & 1 & & & 1 & & \\
\hline 250 & Proechimys brevicauda (Gunther, 1877) & Rata espinosa colicorta & & & & & & & 1 & & & & \\
\hline 251 & Proechimys cuvieri Petter, 1978 & Rata espinosa de Cuvier & & & & & & & 1 & & & & \\
\hline 252 & Proechimys decumanus (Thomas, 1899) & Rata espinosa grande & 1 & 1 & & & & & & & & VU & \\
\hline 253 & Proechimys kulinae da Silva, 1998 & Rata espinosa de Kulina & & & & & & & 1 & & & & \\
\hline 254 & Proechimys pattoni da Silva, 1998 & Rata espinosa de Patton & & & & & & & 1 & & & & \\
\hline 255 & Proechimys quadruplicatus Hershkovitz, 1948 & Rata espinosa del Napo & & & & & & & 1 & & & & \\
\hline 256 & Proechimys simonsi Thomas, 1900 & Rata espinosa de Simons & & & & & & 1 & 1 & 1 & & & \\
\hline 257 & Proechimys steerei Goldman, 1911 & Rata espinosa de Steer & & & & & & & 1 & & & & \\
\hline \multicolumn{14}{|c|}{ Lagomorpha } \\
\hline \multicolumn{14}{|c|}{ Leporidae } \\
\hline & Sylvilagus brasiliensis (Linnaeus, 1758) & Conejo, liebre amazónica & & & & 1 & 1 & 1 & 1 & & & & \\
\hline \multicolumn{14}{|c|}{ Soricomorpha } \\
\hline \multicolumn{14}{|c|}{ Soricidae } \\
\hline & Cryptotis equatoris (Thomas, 1912) & $\begin{array}{l}\text { Musaraña de orejas cortas } \\
\text { ecuatoriana }\end{array}$ & & & & & 1 & 1 & & & & & \\
\hline & $\begin{array}{l}\text { Cryptotis peruviensis Vivar, Pacheco y Valqui, } \\
1997\end{array}$ & Musaraña de orejas cortas peruana & & & & & 1 & 1 & & & 1 & & $\mathrm{VU}$ \\
\hline \multicolumn{14}{|c|}{ Chiroptera } \\
\hline \multicolumn{14}{|c|}{ Emballonuridae } \\
\hline & Centronycteris centralis Thomas, 1912 & $\begin{array}{l}\text { Murciélago peludo de Centro } \\
\text { América }\end{array}$ & & & & & & 1 & 1 & & & & \\
\hline & Centronycteris maximiliani (J. Fischer, 1829) & Murciélago velludo de Maximiliano & & & & & & & 1 & & & & \\
\hline & Cormura brevirostris (Wagner, 1843) & Murciélago de saco ventral & & & & & & & 1 & & & & \\
\hline & Diclidurus albus Wied-Neuwied, 1820 & Murciélago blanco común & & & & & & & 1 & & & & \\
\hline 265 & Diclidurus scutatus Peters, 1869 & Murciélago cremoso & & & & & & & 1 & & & & \\
\hline 266 & Peropteryx kappleri Peters, 1867 & Murciélago de sacos de kappler & & & & & & 1 & 1 & & & & \\
\hline & Peropteryx leucoptera Peters, 1867 & Murciélago de sacos aliblanco & & & & & & & 1 & & & & \\
\hline 268 & Peropteryx macrotis (Wagner, 1843) & Murciélago de sacos orejudo & & & & & & & 1 & 1 & & & \\
\hline 269 & Rhynchonycteris naso (Wied-Neuwied, 1820) & Murcielaguito narigudo & & & & & & & 1 & 1 & & & \\
\hline & Saccopteryx bilineata (Temminck, 1838) & Murcielaguito negro de listas & 1 & & & & & & 1 & 1 & & & \\
\hline 271 & Saccopteryx canescens Thomas, 1901 & Murcielaguito de listas difusas & & & & & & & 1 & & & & \\
\hline & Saccopteryx leptura (Schreber, 1774) & Murcielaguito pardo de listas & & & & & & & 1 & & & & \\
\hline \multicolumn{14}{|c|}{ Phyllostomidae } \\
\hline & Desmodus rotundus (E. Geoffroy, 1810) & Vampiro común & 1 & 1 & 1 & 1 & & 1 & 1 & & & & \\
\hline 274 & Diaemus youngi (Jentink, 1893) & Vampiro aliblanco & & 1 & & & & & 1 & & & & \\
\hline & Diphylla ecaudata Spix, 1823 & Vampiro peludo & & & & & & 1 & 1 & & & & \\
\hline 276 & Anoura aequatoris (Lönnberg, 1921) & Murciélago longirostro de Ecuador & & & & & & 1 & & & & & \\
\hline & Anoura caudifer (E. Geoffroy, 1818) & Murciélago longirostro menor & & & & & & 1 & 1 & & & & \\
\hline 278 & Anoura cultrata Handley, 1960 & Murciélago longirostro negruzco & & & & & & 1 & 1 & & & & \\
\hline & $\begin{array}{l}\text { Anoura fistulata Muchhala, Mena y Albuja, } \\
2005\end{array}$ & $\begin{array}{l}\text { Murciélago longirostro de grandes } \\
\text { labios }\end{array}$ & & & & & & 1 & & & & & \\
\hline & Anoura geoffroyi Gray, 1838 & Murciélago longirostro sin cola & 1 & & 1 & 1 & & 1 & 1 & & & & \\
\hline & Anoura latidens Handley, 1984 & Murciélago longirostro dentudo & & & & & & 1 & & & & & \\
\hline
\end{tabular}




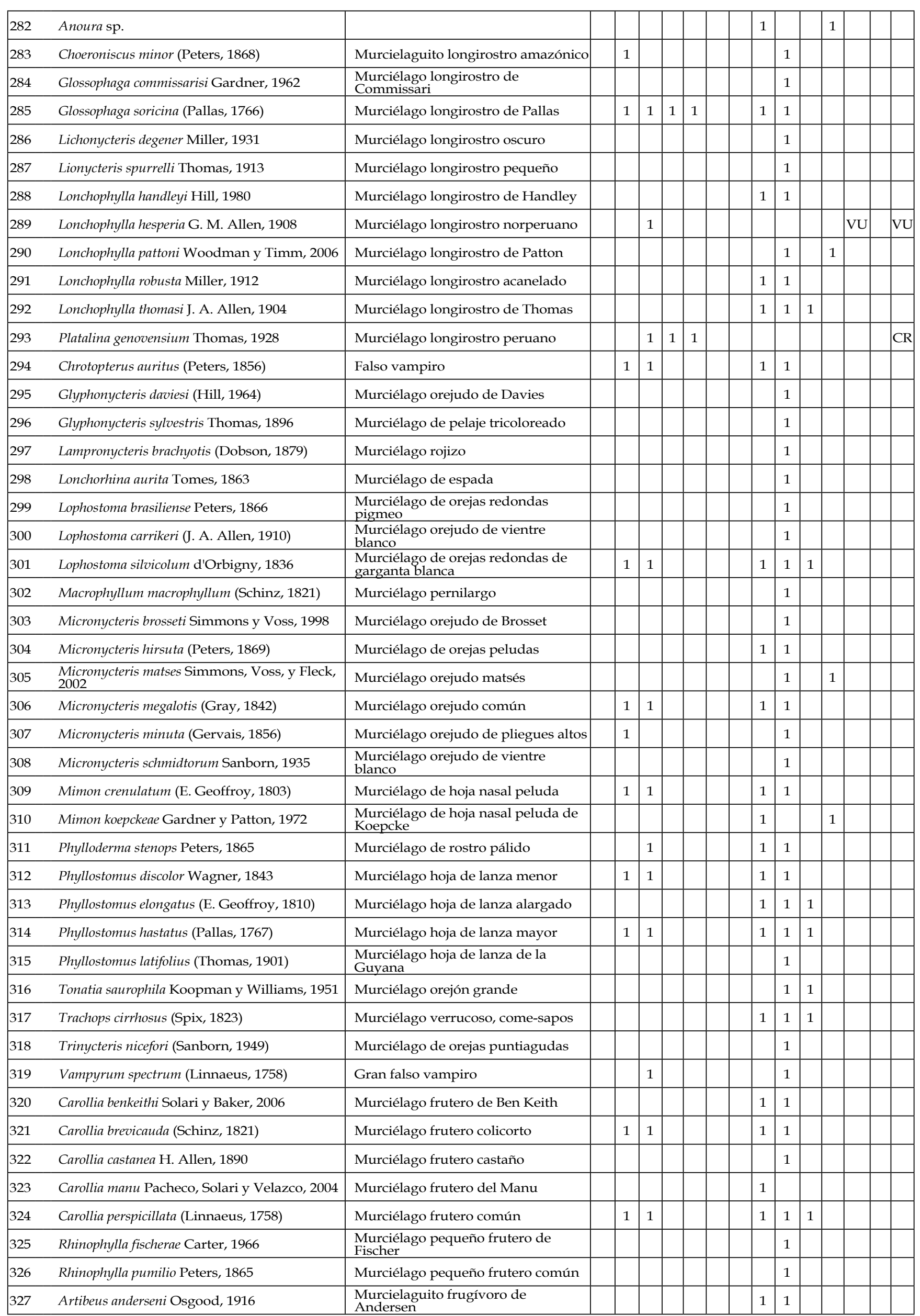


Pacheco et al.

\begin{tabular}{|c|c|c|c|c|c|c|c|c|c|c|c|c|c|}
\hline 328 & Artibeus cinereus (Gervais, 1856) & Murcielaguito frugívoro ceniciento & & & & & & & 1 & & & & \\
\hline 329 & Artibeus concolor Peters, 1865 & Murcielaguito frugívoro pardo & & & & & & & 1 & & & & \\
\hline 330 & Artibeus fraterculus Anthony, 1924 & Murciélago frutero fraternal & 1 & 1 & 1 & 1 & & & & & & & \\
\hline 331 & Artibeus glaucus Thomas, 1893 & Murciélago frutero plateado & & & & & & 1 & 1 & & & & \\
\hline 332 & Artibeus gnomus Handley, 1987 & Murciélago frutero enano & & & & & & & 1 & 1 & & & \\
\hline 333 & Artibeus jamaicensis Leach, 1821 & Murcielaguito frugívoro común & 1 & & & & & & & & & & \\
\hline 334 & Artibeus lituratus (Olfers, 1818) & Murcielaguito frugívoro mayor & 1 & & & & & 1 & 1 & & & & \\
\hline 335 & Artibeus obscurus (Schinz, 1821) & Murcielaguito frugívoro negro & & & & & & 1 & 1 & & & & \\
\hline 336 & Artibeus planirostris (Spix, 1823) & Murciélago frutero de rostro plano & & & & & & 1 & 1 & & & & \\
\hline 337 & Artibeus ravus (Miller, 1902) & Murcielaguito frugívoro occidental & 1 & & & & & & & & & & \\
\hline 338 & Chiroderma salvini Dobson, 1878 & Murciélago de listas claras & 1 & & & & & 1 & 1 & & & & \\
\hline 339 & Chiroderma trinitatum Goodwin, 1958 & Murciélago menor de listas & & & & & & & 1 & 1 & & & \\
\hline 340 & Chiroderma villosum Peters, 1860 & Murciélago de lineas tenues & 1 & & & & & & 1 & & & & \\
\hline 341 & Enchisthenes hartii (Thomas, 1892) & Murciélago frutero aterciopelado & 1 & 1 & & & & 1 & 1 & & & & \\
\hline 342 & Mesophylla macconnelli Thomas, 1901 & Murcielaguito cremoso & & & & & & 1 & 1 & & & & \\
\hline 343 & Platyrrhinus albericoi Velazco, 2005 & $\begin{array}{l}\text { Murciélago de nariz ancha de } \\
\text { Alberico }\end{array}$ & & & & & & 1 & 1 & & & & \\
\hline 344 & $\begin{array}{l}\text { Platyrrhinus brachycephalus (Rouk y Carter, } \\
\text { 1972) }\end{array}$ & $\begin{array}{l}\text { Murciélago de nariz ancha de cabeza } \\
\text { pequeña }\end{array}$ & & & & & & & 1 & & & & \\
\hline 345 & Platyrrhinus incarum (Thomas, 1912) & Murciélago de nariz ancha inca & & & & & & 1 & 1 & & & & \\
\hline 346 & Platyrrhinus infuscus (Peters, 1880) & $\begin{array}{l}\text { Muciélago de nariz ancha de listas } \\
\text { tenues }\end{array}$ & & & & & & 1 & 1 & & & & \\
\hline 347 & Platyrrhinus ismaeli Velazco, 2005 & Murciélago de nariz ancha de Ismael & & & & & & 1 & & & & $\mathrm{VU}$ & \\
\hline 348 & Platyrrhinus masu Velazco, 2005 & Murciélago de nariz ancha quechua & & & & & & 1 & 1 & & & & \\
\hline 349 & Platyrrhinus matapalensis Velazco, 2005 & $\begin{array}{l}\text { Murciélago de nariz ancha de } \\
\text { Matapalo }\end{array}$ & 1 & & & & & & & & & & \\
\hline 350 & Platyrrhinus nigellus Gardner y Carter, 1972 & Murciélago de nariz ancha negrito & & & & & & 1 & & & & & \\
\hline 351 & Sphaeronycteris toxophyllum Peters, 1882 & Murciélago apache & & & & & & & 1 & & & & \\
\hline 352 & Sturnira aratathomasi Peterson y Tamsitt, 1968 & $\begin{array}{l}\text { Murciélago de hombros amarillos de } \\
\text { Aratathomas }\end{array}$ & & & & & & 1 & & & & & \\
\hline 353 & Sturnira bidens Thomas, 1915 & $\begin{array}{l}\text { Murciélago de hombros amarillos de } \\
\text { dos dientes }\end{array}$ & & & & & 1 & 1 & & & & & \\
\hline 354 & Sturnira bogotensis Shamel, 1927 & $\begin{array}{l}\text { Murciélago de hombros amarillos de } \\
\text { Bogotá }\end{array}$ & & & & 1 & & & & & & & \\
\hline 355 & Sturnira erythromos (Tschudi, 1844) & Murciélago frugívoro oscuro & & & & 1 & 1 & 1 & & & & & \\
\hline 356 & Sturnira lilium (E. Geoffroy, 1810) & Murciélago de charreteras amarillas & & & & & & 1 & 1 & 1 & & & \\
\hline 357 & Sturnira luisi Davis, 1980 & $\begin{array}{l}\text { Murciélago de hombros amarillos } \\
\text { de Luis }\end{array}$ & 1 & 1 & & & & & & & & & \\
\hline 358 & Sturnira magna de la Torre, 1966 & $\begin{array}{l}\text { Murciélago de hombros amarillos } \\
\text { grande }\end{array}$ & & & & & & 1 & 1 & & & & \\
\hline 359 & Sturnira nana Gardner y O'Neill, 1971 & Murciélago frugívoro enano & & & & & & 1 & & & 1 & EN & EN \\
\hline 360 & Sturnira oporaphilum (Tschudi, 1844) & $\begin{array}{l}\text { Murciélago de hombros amarillos de } \\
\text { oriente }\end{array}$ & & & & & & 1 & 1 & & & & \\
\hline 361 & Sturnira tildae de la Torre, 1959 & Murciélago de charreteras rojizas & & & & & & & 1 & & & & \\
\hline 362 & Uroderma bilobatum Peters, 1866 & Murciélago constructor de toldos & 1 & & & & & 1 & 1 & 1 & & & \\
\hline 363 & Uroderma magnirostrum Davis, 1968 & $\begin{array}{l}\text { Murciélago amarillento constructor } \\
\text { de toldos }\end{array}$ & & & & & & & 1 & & & & \\
\hline 364 & Vampyressa melissa Thomas, 1926 & $\begin{array}{l}\text { Murciélago de orejas amarillas de } \\
\text { Melissa }\end{array}$ & & & & & & 1 & 1 & & & $\mathrm{Vu}$ & \\
\hline 365 & Vampyressa thyone Thomas, 1909 & $\begin{array}{l}\text { Murciélago de orejas amarillas } \\
\text { ecuatoriano }\end{array}$ & 1 & & & & & 1 & 1 & & & & \\
\hline 366 & Vampyriscus bidens (Dobson, 1878) & Murcielaguito de lista dorsal & & & & & & & 1 & & & & \\
\hline 367 & Vampyriscus brocki Peterson, 1968 & Murcielaguito de Brock & & & & & & & 1 & & & & \\
\hline 368 & Vampyrodes caraccioli (Thomas, 1889) & Muciélago de listas pronunciadas & & & & & & & 1 & & & & \\
\hline \multicolumn{14}{|c|}{ Mormoopidae } \\
\hline 369 & Mormoops megalophylla (Peters, 1864) & Murciélago fantasma & & 1 & & & & & & & & & \\
\hline 370 & Pteronotus davyi Gray, 1838 & Murcielaguito de espalda desnuda & & 1 & & & & 1 & & & & & \\
\hline 371 & Pteronotus gymnonotus Natterer, 1843 & Murciélago de espalda desnuda & & & & & & 1 & 1 & & & & \\
\hline 372 & Pteronotus parnellii (Gray, 1843) & Murciélago bigotudo & & & & & & & 1 & & & & \\
\hline
\end{tabular}




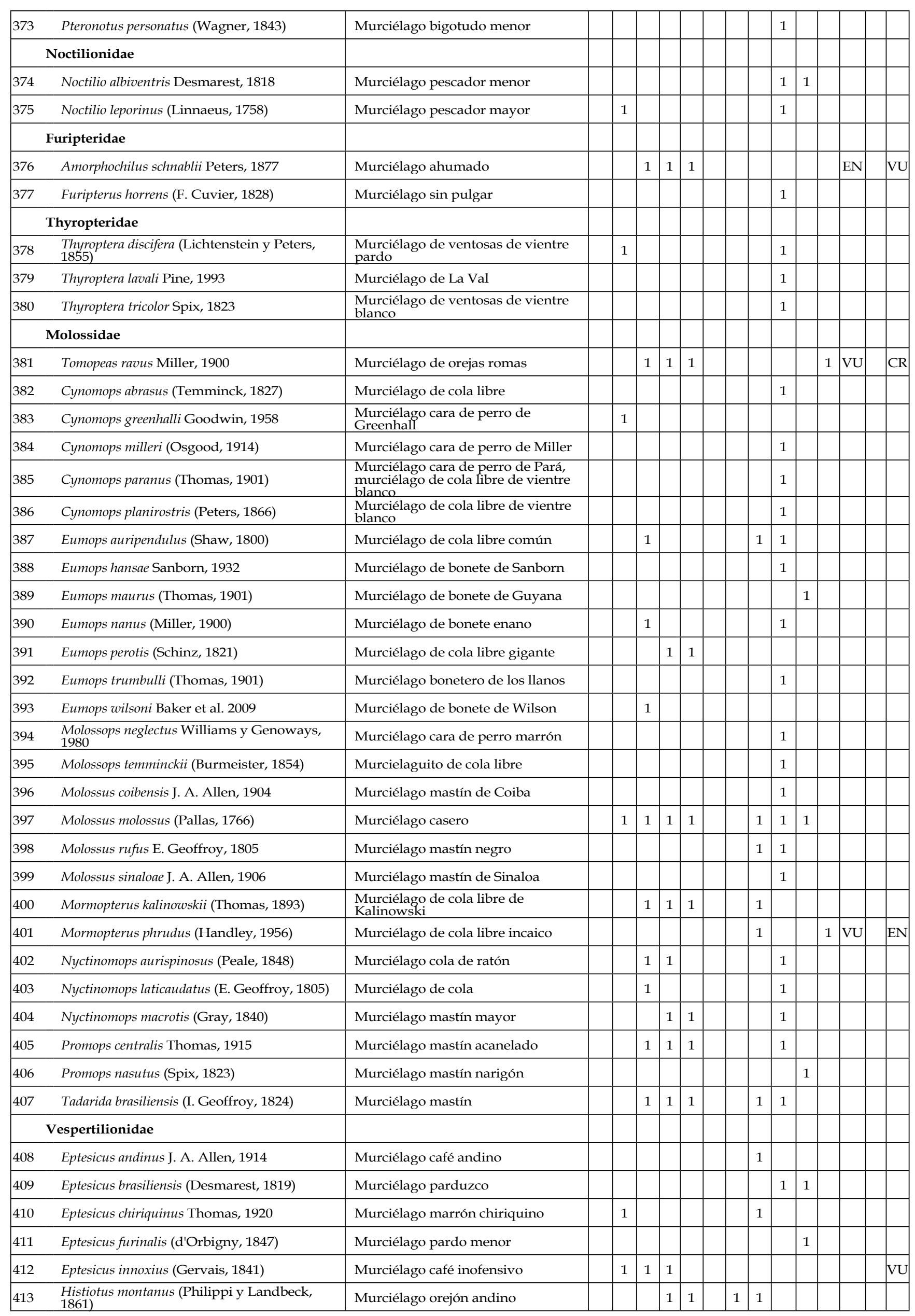


Pacheco et al.

\begin{tabular}{|c|c|c|c|c|c|c|c|c|c|c|c|c|c|c|}
\hline 414 & Histiotus velatus (I.Geoffroy, 1824) & Murciélago orejón del Trópico & & & & & & & 1 & & & & & \\
\hline 415 & Lasiurus blossevillii (Lesson y Garnot, 1826) & Murciélago rojizo & 1 & 1 & 1 & & & & 1 & 1 & & & & \\
\hline 416 & Lasiurus cinereus (Palisot de Beauvois, 1796) & Murciélago escarchado & & & & & & 1 & 1 & 1 & 1 & & & \\
\hline 417 & Lasiurus ega (Gervais, 1856) & Murciélago amarillento & 1 & & & & & & & 1 & & & & \\
\hline 418 & Rhogeessa velilla (Thomas, 1903) & $\begin{array}{l}\text { Murciélago amarillo pequeño de alas } \\
\text { negras }\end{array}$ & 1 & & & & & & & & & & & \\
\hline 419 & Myotis albescens (E. Geoffroy, 1806) & Murcielaguito plateado & 1 & 1 & & & & & 1 & 1 & 1 & & & \\
\hline 420 & Myotis atacamensis (Lataste, 1892) & Murcielaguito de Atacama & & 1 & 1 & 1 & & & & & & & & \\
\hline 421 & Myotis keaysi J. A. Allen, 1914 & Murciélago negruzco & 1 & 1 & & 1 & & & 1 & 1 & & & & \\
\hline 422 & Myotis nigricans (Schinz, 1821) & Murciélago negruzco común & 1 & 1 & 1 & & & & 1 & 1 & & & & \\
\hline 423 & Myotis oxyotus (Peters, 1867) & Murciélago negruzco grande & & & 1 & 1 & & & 1 & 1 & & & & \\
\hline 424 & Myotis riparius Handley, 1960 & Murcielaguito acanelado & 1 & 1 & & & & & 1 & 1 & 1 & & & \\
\hline 425 & Myotis simus Thomas, 1901 & Murciélago vespertino aterciopelado & & & & & & & 1 & 1 & & & & \\
\hline \multicolumn{15}{|c|}{ Carnivora } \\
\hline \multicolumn{15}{|c|}{ Felidae } \\
\hline 426 & Leopardus jacobitus (Cornalia, 1865) & Gato montés, gato andino & & & & & & 1 & & & & EN & I & EN \\
\hline 427 & Leopardus colocolo (Molina, 1782) & Gato del pajonal, oscollo & & & 1 & 1 & & 1 & 1 & & & & II & \\
\hline 428 & Leopardus pardalis (Linnaeus, 1758) & $\begin{array}{l}\text { Ocelote, tigrillo, gato onza, } \\
\text { matsonsori }\end{array}$ & 1 & 1 & & 1 & & & 1 & 1 & & & $\mathrm{I}$ & \\
\hline 429 & Leopardus tigrinus (Schreber, 1775) & Gato tigre común, tigrino & & & & & & & 1 & & & VU & I & \\
\hline 430 & Leopardus wiedii (Schinz, 1821) & Huamburushu, margay & & & & & & & & 1 & 1 & & I & \\
\hline 431 & Puma concolor (Linnaeus, 1771) & $\begin{array}{l}\text { Puma, león, lluichu-puma, kirajari } \\
\text { matsonsori }\end{array}$ & 1 & 1 & 1 & 1 & 1 & 1 & 1 & 1 & & & II & \\
\hline & $\begin{array}{l}\text { Puma yagouaroundi (É. Geoffroy Saint-Hilaire, } \\
\text { 1803) }\end{array}$ & Yahuarundi, eira, postari, matsonsori & 1 & & & & & & 1 & 1 & & & II & \\
\hline 433 & Panthera onca (Linnaeus, 1758) & $\begin{array}{l}\text { Jaguar, otorongo, uturuncu, puágkat, } \\
\text { jenocri }\end{array}$ & 1 & 1 & & & & & 1 & 1 & 1 & & I & \\
\hline \multicolumn{15}{|c|}{ Canidae } \\
\hline & Atelocynus microtis (Sclater, 1883) & $\begin{array}{l}\text { Zorro negro orejicorto, perro de } \\
\text { monte, monte allgo }\end{array}$ & & & & & & & & 1 & 1 & & & \\
\hline 435 & Chrysocyon brachyurus (Illiger, 1815) & Lobo de crín & & & & & & & & & 1 & & II & \\
\hline 436 & Lycalopex culpaeus (Molina, 1782) & Zorro colorado, atoj & & & 1 & 1 & & 1 & & & & & II & \\
\hline 437 & Lycalopex griseus (Gray 1837) & Zorro gris, chilla & & & 1 & 1 & & & & & & & II & \\
\hline 438 & Lycalopex sechurae Thomas, 1900 & Zorro de Sechura, juancito & & 1 & 1 & 1 & & & & & & & & \\
\hline & Speothos venaticus (Lund, 1842) & $\begin{array}{l}\text { Perro de monte, perro de bosque, } \\
\text { zorro vinagre, mashiti }\end{array}$ & & & & & & & 1 & 1 & & & $\mathrm{I}$ & \\
\hline \multicolumn{15}{|c|}{ Ursidae } \\
\hline & Tremarctos ornatus (F. G. Cuvier, 1825) & $\begin{array}{l}\text { Oso de anteojos, ucumari, ucucu, } \\
\text { meéni }\end{array}$ & & 1 & & 1 & 1 & 1 & 1 & & & VU & I & EN \\
\hline \multicolumn{15}{|c|}{ Otariidae } \\
\hline & Arctocephalus australis (Zimmermann, 1783) & Lobo fino, cochapuma & & & 1 & & & & & & & & II & EN \\
\hline 442 & Arctocephalus philippii (Peters, 1866) & Lobo fino de Juan Fernández & & & 1 & & & & & & & & II & \\
\hline & Otaria flavescens (Shaw, 1800) & Lobo chusco, cochapuma & & & 1 & & & & & & & & & $\mathrm{Vu}$ \\
\hline \multicolumn{15}{|c|}{ Mustelidae } \\
\hline & Lontra felina (Molina, 1782) & Gato marino, chingungo, huallaque & & & 1 & & & & & & & EN & I & EN \\
\hline 445 & Lontra longicaudis (Olfers, 1818) & $\begin{array}{l}\text { Lobo pequeño de río, nutria, } \\
\text { mayopuma (aya,apur, Cuzco) }\end{array}$ & & 1 & & 1 & & & & 1 & & & I & \\
\hline 446 & Pteronura brasiliensis (Gmelin, 1788) & $\begin{array}{l}\text { Lobo grande de río, nutria grande, } \\
\text { shabaropa }\end{array}$ & & & & & & & & 1 & 1 & EN & I & EN \\
\hline & Eira barbara (Linnaeus, 1758) & Tejón, manco, omeiro, oáti & 1 & 1 & & & & & 1 & 1 & 1 & & III & \\
\hline & Galictis cuja (Molina, 1782) & Hurón menor, cuya & & & & & & 1 & & & & & & \\
\hline 449 & Galictis vittata (Schreber, 1776) & Hurón grande, grisón & & & & & & & & 1 & & & III & \\
\hline & Mustela africana Desmarest, 1818 & $\begin{array}{l}\text { Comadreja rayada, comadreja } \\
\text { amazónica, katori }\end{array}$ & & & & & & & & 1 & & & & \\
\hline & Mustela frenata Lichtenstein, 1831 & Comadreja, tolompeo, achocalla & & & & 1 & 1 & 1 & 1 & 1 & & & & \\
\hline \multicolumn{15}{|c|}{ Mephitidae } \\
\hline & Conepatus chinga (Molina, 1782) & Zorrino, añás & & & & 1 & & 1 & 1 & 1 & & & & \\
\hline
\end{tabular}


Diversidad de los mamíferos del Perú

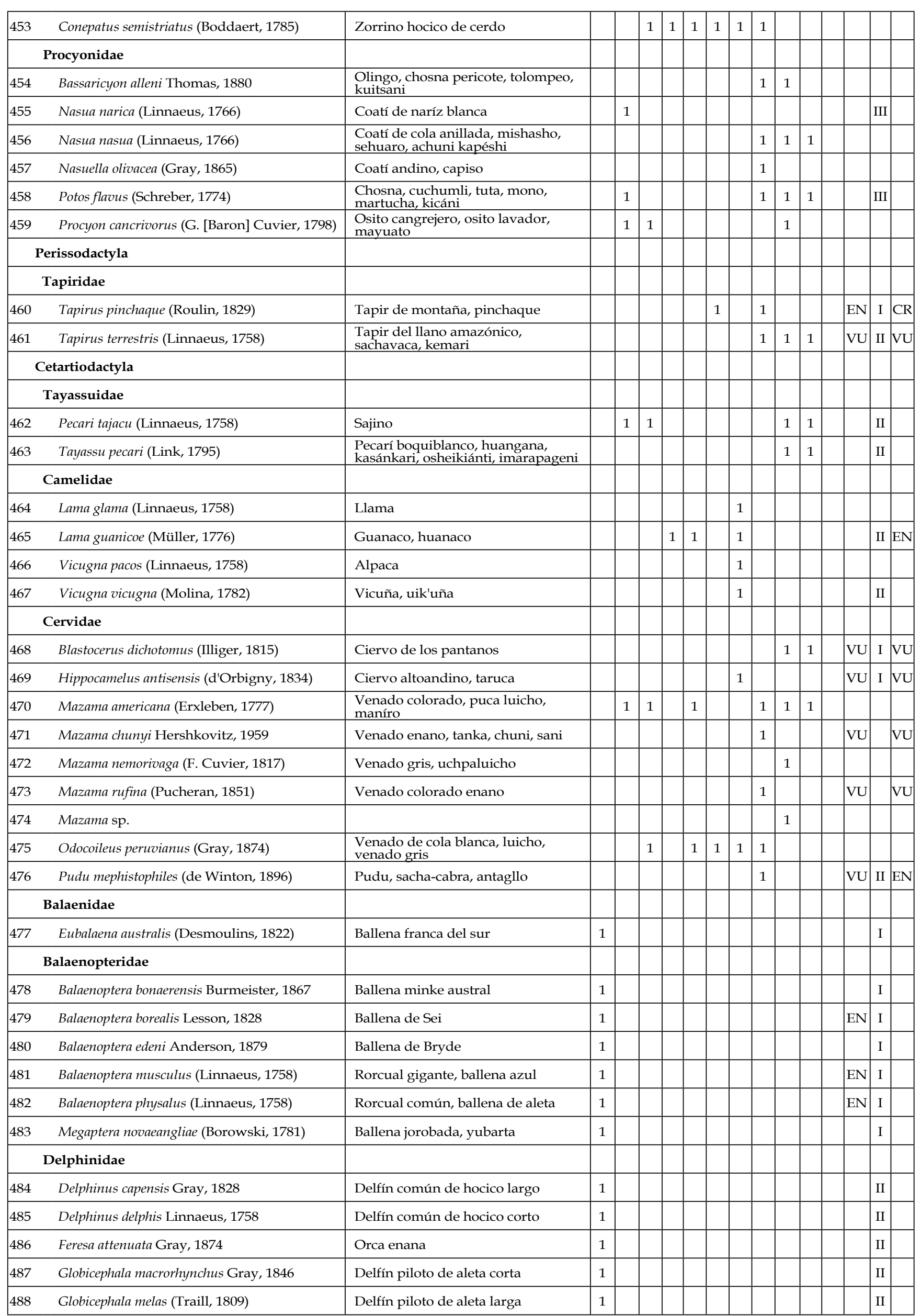


Pacheco et al.

\begin{tabular}{|c|c|c|c|c|c|c|c|c|c|c|c|c|c|c|c|c|}
\hline 489 & Grampus griseus (G. Cuvier, 1812) & Delfín gris, delfín de Risso & 1 & & & & & & & & & & & & II & \\
\hline 490 & Lagenorhynchus obscurus (Gray, 1828) & Delfín obscuro & 1 & & & & & & & & & & & & II & \\
\hline 491 & Lissodelphis peronii (Lacépède, 1804) & Delfín de perón, delfín liso austral & 1 & & & & & & & & & & & & II & \\
\hline 492 & Orcinus orca (Linnaeus, 1758) & Orca verdadera, tonina & 1 & & & & & & & & & & & & II & \\
\hline 493 & Peponocephala electra (Gray, 1846) & Delfín cabeza de melón & 1 & & & & & & & & & & & & II & \\
\hline 495 & Sotalia fluviatilis (Gervais y Deville, 1853) & Bufeo gris, bufeo negro & & & & & & & & & 1 & & & & $\mathrm{I}$ & \\
\hline 496 & Stenella attenuata (Gray, 1846) & $\begin{array}{l}\text { Delfín con brida, delfín manchado } \\
\text { pantropical }\end{array}$ & 1 & & & & & & & & & & & & II & \\
\hline 497 & Stenella coeruleoalba (Meyen, 1833) & Delfín rayado, delfín listado & 1 & & & & & & & & & & & & II & \\
\hline 498 & Stenella longirostris (Gray, 1828) & Delfín hilandero, delfín tornillo & 1 & & & & & & & & & & & & II & \\
\hline 500 & Tursiops truncatus (Montagu, 1821) & Delfín pico de botella & 1 & & & & & & & & & & & & II & \\
\hline \multicolumn{17}{|c|}{ Phocoenidae } \\
\hline 501 & Phocoena spinipinnis Burmeister, 1865 & Marsopa espinosa, chancho marino & 1 & & & & & & & & & & & & II & \\
\hline \multicolumn{17}{|c|}{ Physeteridae } \\
\hline 502 & Kogia breviceps (Blainville, 1838) & Cachalote de cabeza pequeña & 1 & & & & & & & & & & & & II & \\
\hline 503 & Kogia sima (Owen, 1866) & Cachalote enano & 1 & & & & & & & & & & & & II & \\
\hline 504 & Physeter catodon Linnaeus, 1758 & Cachalote & 1 & & & & & & & & & & & $\mathrm{VU}$ & $\mathrm{I}$ & \\
\hline \multicolumn{17}{|c|}{ Iniidae } \\
\hline 505 & Inia geoffrensis (Blainville, 1817) & Bufeo colorado & & & & & & & & & 1 & & & & II & \\
\hline \multicolumn{17}{|c|}{ Ziphiidae } \\
\hline 508 & Ziphius cavirostris G. Cuvier, 1823 & Ballena de pico de Cuvier & 1 & & & & & & & & & & & & II & \\
\hline & Total especies & & 30 & 65 & 60 & 46 & 63 & 23 & 63 & 210 & 292 & 60 & 65 & 54 & 75 & 59 \\
\hline
\end{tabular}

